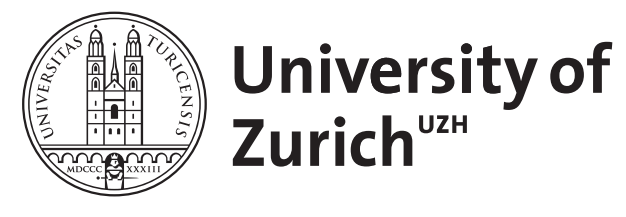

\title{
The executive turnover risk premium
}

Peters, Florian S ; Wagner, Alexander F

\begin{abstract}
CEO compensation has increased substantially over the past 15 years, but so has forced turnover. Motivated by this observation, we investigate whether part of the development of CEO pay can be explained by a premium which compensates CEOs for increased job risk. We find that for the CEOs of the largest US corporations, a one percentage point increase in turnover risk is, on average, associated with about $4 \%$ more in terms of total compensation. This relation is much stronger in the cross section than it is over time, and it does not appear to be driven by endogeneity. Our findings are consistent with a model of effcient contracting, but are harder to reconcile with a model of entrenched CEOs.
\end{abstract}

DOI: https://doi.org/10.1111/jofi.12166

Posted at the Zurich Open Repository and Archive, University of Zurich ZORA URL: https://doi.org/10.5167/uzh-61007

Journal Article

Accepted Version

Originally published at:

Peters, Florian S; Wagner, Alexander F (2014). The executive turnover risk premium. Journal of Finance, 69(4):1529-1563.

DOI: https://doi.org/10.1111/jofi.12166 


\title{
The Executive Turnover Risk Premium
}

\author{
Florian S. Peters and Alexander F. Wagner*
}

September 13, 2013

Forthcoming, The Journal of Finance

\begin{abstract}
We establish that CEOs of companies experiencing volatile industry conditions are more likely to be dismissed. At the same time, industry risk is, accounting for various other factors, unlikely to be associated with CEO compensation other than through dismissal risk. Using this identification strategy, we document that CEO turnover risk is significantly positively associated with compensation. This finding is important because job-risk compensating wage differentials arise naturally in competitive labor markets. By contrast, the evidence rejects an entrenchment model according to which powerful
\end{abstract} CEOs have lower job risk and at the same time secure higher compensation.

* Peters: University of Amsterdam. Address: Finance Group, Roetersstraat 11, 1018 WB Amsterdam, The Netherlands, email: f.s.peters@uva.nl. Wagner: Swiss Finance Institute (University of Zurich), CEPR, ECGI, and Harvard University. Address: Department of Banking and Finance, Plattenstrasse 14, CH-8032 Zurich, Switzerland, Phone: +41(44) 634-3963. Email: alexander.wagner@bf.uzh.ch. We thank Cam Harvey (the editor), an anonymous associate editor, and an anonymous referee for excellent comments. We are grateful to Zhonglan Dai, Cristian Dezsö, Florian Eugster, Dirk Jenter, Greg Nini, Bob Parrino, and Luke Taylor for generously sharing data from their respective papers. We thank Darrell Duffie, Rajna Gibson, Stuart Gillan, Michel Habib, Jay Hartzell (AFA discussant), Fritz Henderson, Mark Huson, Dirk Jenter, Gary King, Camelia Kuhnen, Michael Lemmon, Ulrike Malmendier, Kasper Meisner Nielsen, Enrico Moretti, Kevin Murphy, Bob Parrino, Josh Pollet, Zacharias Sautner, Laura Starks, René Stulz, Michael Wolf, David Yermack, and Jeffrey Zwiebel for discussions, and seminar participants at the CEPR European Summer Symposium in Financial Markets, the FMA Asian Conference, the NCCR FINRISK annual meeting, the SFI annual meeting, the Midwest Finance Association conference, the University of Vienna, the Helsinki School of Economics, UNC, Cranfield University, Amsterdam Business School, UC Berkeley, University of Geneva, University of Mannheim, and Georgia State University for comments. We also thank the Swiss Finance Institute, the NCCR FINRISK and the University of Zurich Research Priority Program "Finance and Financial Markets" for financial support. Wagner expresses his heartfelt thanks to Christina Aiko Mayer for her simply wonderful support. 
This paper investigates the idea that turnover risk is priced in executive compensation. In light of the ongoing discussion about pay practices in U.S. corporations and worldwide, understanding this relationship is of particular interest. A positive association between dismissal risk and pay in the cross section of CEOs is a central prediction of a competitive labor market model: In such a model, pay in "constrained" sectors (where job risk exists and results in costs for dismissed employees) needs to be higher than in "unconstrained" sectors to compensate for job risk (Abowd and Ashenfelter, 1981). Consistent with this hypothesis, our results provide considerable evidence that CEOs who are exposed to higher job risk are paid more than CEOs enjoying more secure jobs. $^{1}$

By focusing on the cross-sectional relationship between dismissal risk and compensation, our study complements that of Kaplan and Minton (2012) who document a secular downward trend in CEO tenures and argue that the shorter expected tenure of CEOs "likely offsets some of the benefits of the increase in CEO pay" (p. 27) over the past 15 years, suggesting a link between dismissal risk and compensation in the time series (see also Kaplan (2008)).

Previous work has shown that CEOs bear significant costs when getting fired, and so the existence of a turnover risk premium in CEO pay is not surprising per se. Empirical studies show that CEOs may remain unemployed for extended periods of time, and when they find a new job, they typically work for much smaller firms and earn significantly less than in their prior job (Fee and Hadlock, 2004). ${ }^{2}$

But is variation in turnover risk causally related to compensation? To answer this question, the natural empirical approach is to estimate job risk of CEOs in a first stage and to then relate this predicted job risk to their compensation levels in a second stage. We employ this approach, but we are mindful of the fact that several firm and CEO characteristics that are associated with turnover are arguably also directly related to compensation. Our task, therefore, is to identify factors providing exogenous variation in turnover risk that do not affect pay through other channels.

Our identification strategy relies on the idea that, in practice, firing does not only occur following poor idiosyncratic performance through which the CEO revealed low skill. Rather, a 
board may fire a CEO when industry conditions change. For example, after a technology shock the set of characteristics a CEO offers may no longer fit the new industry characteristics (Eisfeldt and Kuhnen, 2013). Therefore, we hypothesize that CEOs in industries characterized by more uncertain business conditions are more likely to be dismissed. In short, industry risk should predict forced turnover.

As proxies for industry risk we use industry-level equity volatility and the credit rating. These variables signal different, but related types of potential changes of needs in the industry, making it more likely that a board will find it optimal to replace a CEO.

We first document that CEOs are in fact exposed to more job risk when firm and industry conditions are more changeable. To the best of our knowledge, this is a novel empirical result. (We also confirm earlier findings showing that realized industry performance predicts CEO dismissals (Jenter and Kanaan, 2011; Kaplan and Minton, 2012).)

Next, we argue that the degree of changeability of business conditions is unlikely to directly affect CEO compensation, accounting for various other factors such as pay structure, incentives, and several other firm, CEO, and governance characteristics.

As a measure of CEO pay, we not only use market values of compensation, but also riskadjusted, subjective values, which correspond to cash equivalents that CEOs would be willing to accept instead of compensation packages that include equity-based pay. Subjective values of compensation thus take into account the fact that equity-based compensation is worth less to a risk-averse, underdiversified CEO than to an optimally diversified investor. This approach allows us to directly adjust CEO pay for differences in pay structure, alleviating the concern that the dismissal risk premium we observe partially reflects compensation for the riskiness of equity-based pay (which is more widely used where firm or industry risk is high).

We also account for a range of other factors considered to influence pay, such as firm size and corporate governance. In addition, we control for several proxies of CEO skill such as idiosyncratic returns, CEO age, CEO tenure, and outsider status. This attenuates the concern that more difficult jobs may entail higher turnover risk, and, at the same time, require greater CEO skills, which need to be compensated as a skill premium rather than, or in addition to, a dismissal risk 
premium. Moreover, we include proxies for incentives. This alleviates the concern that CEOs receiving more equity-based pay may work harder and may, thus, require an effort cost premium.

Our central finding is that there is a robust and significantly positive association between predicted turnover risk and $\mathrm{CEO}$ compensation. Across various regression specifications and for typical parameter values for CEO risk aversion and for the portfolio diversification constraint the CEO faces, a one percentage point increase in turnover risk is associated with about $7 \%$ greater subjective values of compensation. This is in line with calibrated theoretical predictions.

We also document in reduced form regressions that in industries where contractual severance agreements are rare - implying that a CEO is unlikely to have a severance agreement - industry risk is more strongly compensated through flow compensation. This is consistent with the notion that uninsured job risk leads to a higher dismissal risk premium than job risk that is to some extent insured.

Additionally, the results hold both when using the standard press-based classification and a purely age-based classification of forced turnover. The latter classification categorizes a turnover as forced if the $\mathrm{CEO}$ was below a certain age at the time of departure. It avoids biases in the press-based classification that may arise from varying degrees of media coverage of CEO turnover. It also allows us to investigate another conjecture: A turnover at a younger age is more likely to reflect dismissal rather than retirement. Therefore, the estimated turnover risk premium should be higher at lower age thresholds. This is what we find.

Overall, our results provide evidence in support of the hypothesis that job risk is compensated in the cross section of CEO pay. This is in line with the view that, in this respect, pay in CEO labor markets is set competitively.

Notably, our findings are opposite to a prediction of a simple model where pay is determined by CEO entrenchment or power. Specifically, if more powerful CEOs are able to set their own pay and job security while others are not, that would imply a negative correlation between turnover risk and compensation in the cross section. The reason is that entrenched CEOs would aim for higher compensation and lower turnover risk while the less powerful CEOs would be more moderately paid and, at the same time, exposed to higher turnover risk. This is not what the 
data show. We discuss these implications in more detail in the conclusion.

Three guideposts can be used to put our findings into the context of the literature. First, we note a difference to the mechanism proposed by Hermalin (2005). He argues that increased board scrutiny, that aims to identify the manager's skill, forces CEOs to work harder. Consequently, pay must rise to compensate for the additional disutility of effort. In contrast, our empirical identification relies on the fact that in riskier external environments firing is often the result of a change in the optimal CEO-firm match. Because boards fire more in changing industry conditions, these CEOs need to receive higher compensation in equilibrium than their counterparts.

Second, our finding of a cross-sectional link between CEO dismissal risk and pay is related to and complements the idea of a time-series connection between these two quantities, as proposed by Kaplan and Minton (2012). ${ }^{3}$ While establishing causality in the time series is difficult, our data show that aggregate fluctuations in industry risk over the past decades are consistent with the parallel evolution of CEO pay levels and turnover over the same time period. ${ }^{4}$

Finally, our findings add to the literature on executive compensation and corporate governance more broadly. While several recent theories have aimed at explaining the development of CEO pay levels over time, their insights also apply to the cross section. Gabaix and Landier (2008) show that the secular rise in executive pay can be explained by the similar increase in firm size within a framework of competitive markets and rare skills. Bebchuk and Fried (2004) advocate the managerial entrenchment view in explaining excessive executive pay. Hall and Murphy (2003) argue that total compensation may to a large extent be driven by stock market valuations, as a significant share of CEO pay is equity-based. We control for all of these factors in our regressions and include time dummies to capture general developments such as trends in the composition of skills (Murphy and Zaboinik, 2004; Frydman, 2005). Thus, our contribution is to show that a significant fraction of the cross-sectional variation in CEO pay can be explained by dismissal risk even after controlling for other important determinants of CEO pay.

The paper is organized as follows. Section I discusses our empirical strategy. In Section II we describe the data. Section III presents the results. Section IV concludes. 


\section{Empirical Strategy}

The theoretical argument for why CEOs facing higher dismissal risk may get paid more is simple: A job loss comes with costs for the CEO, such as a deterioration of future earnings opportunities and uncertainty about the duration of the unemployment spell. Thus, in competitive labor markets job risk needs to be compensated with higher pay (Abowd and Ashenfelter, 1981). ${ }^{5}$ However, the fundamental challenge this paper must address is that turnover risk is endogenous. To estimate the causal effect of turnover risk on compensation, we need to compare the compensation of a $\mathrm{CEO}$ who faces a given turnover risk with the counterfactual compensation that would have been observed had turnover risk been different for exogenous reasons. Ideally, we would like to randomly assign varying degrees of turnover risk to a sample of CEOs and relate these to the resulting levels of compensation. In observational data, the causal effect can instead be identified using instrumental variables, i.e., variables that significantly affect turnover risk, but are unrelated to CEO pay except through their effect on turnover.

\section{A. Instrumental Variables}

We argue that the uncertainty of industry conditions, or industry risk, provides a valid instrumental variable for forced turnover in our analysis.

The motivation for this instrument is as follows. It is clear that boards fire CEOs for poor firm (idiosyncratic) performance. More surprisingly, Jenter and Kanaan (2011) and Kaplan and Minton (2012) document that boards are also more likely to fire a CEO when industry performance is poor. While this empirical fact is puzzling from the perspective of standard models of relative performance evaluation, Eisfeldt and Kuhnen (2013) provide a competitive assignment model in which industry shocks change the outside options of firms and managers, making it optimal for boards to include industry conditions in their decision to terminate the current CEO. Intuitively, shocks to an industry's technology or productivity may imply that a different managerial skill set is required.

These existing results concern realized firm or industry performance as a determinant of turnover. We build on these ideas and conjecture that, ex ante, in volatile industry conditions, 
the match between the CEO's skill set and the requirements in his industry is more likely to weaken, leading the board to fire the CEO. Thus, we hypothesize that industry risk predicts CEO turnover.

We use two proxies for changing business conditions. Our first measure is stock return volatility. More volatile equity prices signal a more changeable environment. On the industry level, equity volatility arguably reflects largely exogenous technology, productivity, or demand shocks. In practice, boards may be particularly attentive to uncertainty when it comes to downside risks. As our second measure we, therefore, use firms' long-term credit ratings. Ratings focus explicitly on the probability of bad realizations or default risk. They also take into account additional and more complex criteria than volatility alone and could, therefore, measure additional aspects of uncertainty regarding future conditions not reflected in stock prices. The variable construction is detailed in Section II With a correlation coefficient of $60.4 \%$, the two variables are highly but not perfectly correlated, indicating that they measure the same underlying factor. (We also construct a third measure, semi-volatility, which, similar to ratings, emphasizes downside risk. Since the correlation between volatility and semi-volatility is high and the results using this alternative measure are very similar, we relegate all results using this measure to the Internet Appendix.)

The industry-level versions of volatility and ratings mitigate a concern with firm-level instruments, namely, that firm risk may be driven by CEO skill. Stock returns may be more volatile (rather than just low), and ratings may be worse under a poorly skilled CEO. Without perfect controls for CEO skill, such a channel would bias against finding a positive turnover risk premium. Industry-level measures are arguably unrelated to the skill of the individual CEO while still affecting firm-level risk and thus turnover risk.

\section{B. Accounting for Covariates}

We note that risk - whether measured at the firm level or the industry level - exhibits a close relation to pay levels through the compensation structure. Riskier firms typically pay

their CEOs more equity-based compensation. And, market values of compensation include a compensating differential for the riskiness of stock and stock options. Hence, greater market 
values of compensation in more volatile industries may be the result of differences in pay structure, not only of differences in turnover risk.

To address this concern, we compute cash equivalents that CEOs would be willing to accept instead of compensation packages that include equity-based pay. These risk-adjusted, subjective compensation values explicitly take into account risk aversion and underdiversification of executives. Provided a correct model specification, they adjust the market value of compensation for the pay structure-related risk premium.

In the context of our identification strategy, which is based on industry risk, we require a subjective valuation framework that allows the CEO to optimally respond to risk exposure. First, the CEO can reduce his effective risk exposure by exercising options early and by investing the cash in safer assets. Moreover, the CEO can partially undo his exposure to systematic risk implied by his company stock and option holdings by allocating less outside wealth to the market portfolio. Valuation models that do not incorporate these two features tend to imply too high a risk discount in compensation values.

Several models, including Hall and Murphy (2002), Cai and Vijh (2005) and Ingersoll (2006) contain the first feature (early exercise), while the latter two models incorporate both features. ${ }^{6}$ An advantage of the Ingersoll (2006) model is that it provides closed-form solutions for most expressions and does not require numerical computations of integrals. Therefore, this is the model we use for the main analysis in this paper. The variable construction and parameter choice are described in detail in Section II and in Internet Appendix A. A Stata program implementing this model is available from the authors' websites. ${ }^{7}$

Finally, we are mindful of the fact that the exogeneity of our instruments is plausible only conditional on a range of control variables. Thus we include a number of variables that have been argued (or documented) to determine CEO pay. These variables are realized performance measures, firm size, CEO characteristics, incentives, as well as various governance measures.

Overall, we cannot completely exclude the possibility that unobserved variables bias the estimated effect of turnover risk on pay upwards or downwards, depending on the nature of the omitted variables. However, we believe that the adjustment of the CEO pay variable, the use of 
industry-level instrumental variables, and the inclusion of many key control variables justify our identifying assumption.

\section{Empirical Model}

We conduct a two-stage least squares approach. The first stage estimates the following linear probability model:

$$
\operatorname{Forced}_{i t}=\alpha_{1}+X_{i t} \beta_{1}+\gamma_{1} Z_{i t}+\theta_{1 t}+\epsilon_{1 i t}
$$

where Forced $_{i t}$ is a dummy variable indicating whether the CEO was fired in a given year, $X_{i t}$ is a vector of controls described earlier which includes some lagged variables, $\theta_{1 t}$ is a full set of year dummies, and $\epsilon_{1 i t}$ is a stochastic error term. $Z_{i t}$ is our instrumental variable, which measures industry risk. The index "1" references the first stage. Naturally, we omit industry dummies in the regressions, as we have a specific theory as to which industry features affect turnover risk.

Note that even though Forced $_{i t}$ is an indicator variable, the linear probability model yields consistent second-stage estimates (Angrist and Krueger, 2001). Using a Probit or Logit model instead can harm consistency of the second-stage estimates and complicates the computation of standard errors (see Bennedsen, Nielsen, Perez-Gonzalez, and Wolfenzon (2007) and Oyer (2008) for applications).

The second stage estimates the effect of forced turnover risk on compensation:

$$
\operatorname{Ln}(\text { Compensation })_{i t}=\alpha_{2}+X_{i t} \beta_{2}+\gamma_{2} \widehat{\operatorname{Forced}}_{i t}+\theta_{2 t}+\epsilon_{2 i t}
$$

where $\operatorname{Ln}(\text { Compensation })_{i t}$ is the log of total CEO compensation and $\widehat{\text { Forced }}_{i t}$ is the predicted value from regression (1). Similar to equation (1), $\theta_{2 t}$ is a set of year dummies, and $\epsilon_{2 i t}$ is the error term. As discussed above, we use two alternative approaches to measure compensation.

By including year dummies in both stages, our identification strategy emphasizes crosssectional variation in the changeability of firm and industry conditions and as such mainly speaks to cross-sectional variation in pay. 
The coefficient of interest is $\gamma_{2}$ which measures the elasticity of CEO compensation with respect to forced turnover risk. Because Forced $_{i t}$ is a dichotomous variable, predicted values from regression (1) are interpreted as probabilities, so that $\gamma_{2}$ measures the percentage change in CEO pay that is associated with a one percentage point increase in the forced turnover probability.

\section{Data}

We study compensation and dismissal risk of CEOs in the 1993 to 2009 ExecuComp sample. Identifying the true nature of a CEO turnover is not straightforward as firms almost never announce a turnover as being involuntary. The most widely used procedure to classify turnovers as "forced" follows Parrino (1997) and uses press reports along with an age criterion and further refinements. We assemble a dataset that relies on this algorithm, based on our own efforts and those of several other authors. ${ }^{8}$ Our dataset includes 3,360 CEO turnovers of which 799 are classified as forced using the press-based procedure.

We also construct an alternative indicator of forced turnover, which entails no interpretation of press reports. This indicator classifies a turnover as forced if the CEO is below a particular age at the time of departure. An important advantage of the age-based turnover classification is its robustness to biases resulting from the extent of press coverage. According to Core, Guay, and Larcker (2011), the number of press articles discussing CEO pay increased substantially in the 1990s. If there has been a similar rise in press coverage of CEO turnover, then the rise in pressreported CEO dismissals may be the result of the breadth of press coverage rather than of a rise in actual dismissals. The age-based algorithm produces false negatives among the turnovers above the respective age threshold and false positives among the turnovers below the age threshold. By comparison, the press-based classification likely produces some false negatives (not all forced turnovers are identified as such in the available press sources) but is unlikely to yield false positives (turnovers described as involuntary by the media typically are indeed involuntary). The pressbased measure thus probably understates the true incidence of forced CEO turnover. For the age-based classification, we use a range of age thresholds: 45, 50, 52, 54, 56, 58, 60, 65, and 70

years. A threshold of 56 closely matches the average dismissal rate resulting from the press-based 
classification.

We assign a one to the Forced dummy (or the respective age-based forced turnover dummy) in the last fiscal year in which a dismissed CEO is in office for the greater part of the fiscal year. We use this timing convention, because, in the case of a transition within a fiscal year, ExecuComp records the compensation of the CEO who was in office for the greater part of that fiscal year. Thus, by using this convention, we ensure that forced turnover and compensation pertain to the same CEO. (In contrast, if we assigned a one to the first year a dismissed CEO is no longer in office for the greater part of the fiscal year, the compensation recorded in ExecuComp would correspond to that of the successor CEO.)

From ExecuComp's compensation data we extract total compensation (item $t d c 1$ ) and convert it to 2000 dollars using the Consumer Price Index provided by the Bureau of Labor Statistics.

We also compute subjective values of total compensation. As explained in Section I, we use the Ingersoll (2006) model for the main analysis in the paper. Internet Appendix A describes the details of the model and its implementation.

Two unobservable model parameters merit special attention: the manager's degree of relative risk aversion, $\rho$, and the portfolio constraint, $\theta$. It is often assumed that $\rho$ is between 2 and 3 for typical economic agents, and we use $\rho=3$ for our main analysis. However, Graham, Harvey, and Puri (2013) show that CEOs are far less risk-averse than the average population. Only 10\% of CEOs exhibit relative risk aversion above 3.78 (whereas this is true for about $60 \%$ in the general population). Our results are stronger with lower levels of CEO risk aversion. Hence, we regard our risk aversion assumption as conservative. Nonetheless, we conduct a robustness analysis showing that our results hold even for relative risk aversion of 5 .

The portfolio constraint, $\theta$, is the fraction of wealth that the manager is forced to hold in his firm's stock beyond that which he would voluntarily hold. Hence, this parameter is determined by the CEO's unvested holdings of company stock and options, not by his total holdings. For our main analysis, we use a value of $\theta=50 \%$, but our robustness analysis shows that our results hold even for $\theta=80 \%$. We regard $\theta=50 \%$ as a conservative choice. ${ }^{9}$

We add to this dataset accounting data from Compustat and stock return data from CRSP. 
As our measure of firm size we use (the log of) total assets. We control for growth opportunities by including Tobin's Q. As measures of short-term stock performance, we use the one-year stock return which we decompose into its market, industry, and idiosyncratic components. The market component is the CRSP equally-weighted market return. The industry component is the equallyweighted industry return minus the market return. The idiosyncratic return is the individual return minus the industry return. We classify industries into 48 groups using the Fama-French classification (Fama and French, 1997) and use the industry returns provided by Ken French.

We pay particular attention to the time period over which stock returns are measured. Studies of CEO turnover typically use stock returns measured over fiscal years - either current or lagged years - as a determinant of CEO turnover. A potential concern with this timing convention is that, when using lagged-year performance, there may be a significant gap between the CEO's departure date and the performance measurement period. For instance, for a CEO that is fired at the end of the fiscal year, the lagged-year performance would neglect the most recent 12 months of performance realized under the departing CEO. On the other hand, when using current fiscal year performance, the measurement period often overlaps with the firing date and thus includes performance that should be attributed to the successor CEO. To address these issues, we measure performance over a period that covers the 12 months prior to the announcement date of a fired $\mathrm{CEO}$, and the current fiscal year performance in case the CEO was not fired.

Two variables measure the extent of variability in firm and industry conditions. First, we compute stock return volatility from monthly return data over the past 48 months. Second, we add the S\&P long-term issuer credit ratings from Compustat. Compustat maps the official rating categories into integer values from 2 (AAA) to 23 (CC). Thus, higher numbers correspond to worse ratings and thus higher distress risk. In the regressions, we scale these numbers such that a unit increase in our rating variable corresponds to the difference between a AAA and a BBB rating, or to the difference between a BBB and a CCC rating (the scaling factor is $1 / 9) .{ }^{10}$ Finally, we construct industry-level measures of these risk proxies: We compute industry volatility using 10-year windows of the equal-weighted returns of the Fama-French 48 industries, and we compute the industry rating as the average $\mathrm{S} \& \mathrm{P}$ rating of all firms in the industry. In the main analysis, 
we lag the instruments by one fiscal year to reduce potential simultaneity concerns. (The results are similar if we use the contemporaneous variables.)

We add CEO variables and incentive measures. Using ExecuComp item datebecameceo (the date the executive became $\mathrm{CEO}$ of the firm), we compute CEO tenure at each fiscal year end, and round it to full integers. We also construct a dummy variable indicating whether a CEO is above the age of 60 . This accounts for the likely non-linearity of the relation between CEO age on the one hand and dismissal risk and pay on the other. We identify chairman-CEOs from ExecuComp's titleann and ceoann fields. We further construct a dummy variable indicating whether the CEO was hired from inside or outside the firm. The classification approach follows Weisbach (1988); a CEO is an outside hire if he joined the firm no earlier than one year before his appointment as CEO. We first use ExecuComp items joined_co (the date when the executive joined the company) and datebecameceo as well as information on whether, prior to becoming CEO, the new CEO was a proxy-named executive for more than a year. We then supplement the dataset with data kindly provided to us by Bushman, Dai, and Wang (2010), Dai, Jin, and Zhang (2012), and Dirk Jenter.

To measure incentives, we construct a dummy variable indicating whether the CEO received stock or stock options in a given year. Moreover, we compute dollar incentives as the sensitivity to the stock price of the CEO's total portfolio of current and outstanding prior grants of shares and options following the methodology in Core and Guay (2002) and Hayes, Lemmon, and Qiu (2012). Specifically, this variable measures the dollar change in the value of the CEO's portfolio for a $1 \%$ change in the stock price. We winsorize dollar incentives at the 99th percentile.

For the time period 2006 to 2009, data on estimated payments in the event of involuntary termination (severance agreements) are available in ExecuComp (item term_pymt), and we construct a dummy variable indicating whether the CEO had a severance agreement in a given year.

Finally, for measures of corporate governance, we compute, from RiskMetrics, (the log of) board size and an indicator variable for whether the majority of directors is independent. This indicator is set to 1 for all firms in the years 2006 to $2009 .{ }^{11}$ We also include a governance index following Gompers, Ishii, and Metrick (2003). The original index is available only for the period 1990 to 2006 . For the years 2007 to 2009, RiskMetrics provides data on most, but not all of the 
original anti-takeover provisions. We construct a modified GIM-index with these variables for all years, 1993 to $2009 .^{12}$

All variable definitions are summarized in Table I.

[Table I approximately here]

The final sample used in the main regressions of Table $\mathrm{V}$ has between 22,379 and 7,625 CEOyear observations, depending on which variables are included. Regressions using individual firm ratings contain substantially fewer observations as several firms do not carry a S\&P long-term issuer credit rating, and governance variables are not available for all firms.

Table II reports descriptive statistics. Panel A presents basic turnover statistics. Panel B contains CEO compensation characteristics. Total compensation is skewed with a mean (median) of about $4.4(2.2)$ million dollars. The mean and median of subjective values of compensation are somewhat lower as CEOs discount equity-based pay due to its riskiness. About four fifths of CEOs receive some form of equity-based pay, though this number varies somewhat over time (not shown in the table). Dollar incentives are about 0.6 million on average. About two thirds of CEOs have a severance agreement in the 2006 to 2009 period. Panel C reports firm characteristics. The mean (median) value of total assets is around 12.3 (1.5) billion dollars. Industry stock return volatility is $23 \%$ on average. The numerical analogue of industry ratings is on average 12 , slightly

below a triple-B rating. Panel D presents statistics on basic CEO characteristics. Corporate governance variables are given in Panel E.

[Table II approximately here]

\section{Results}

\section{A. Determinants of Forced Turnover}

Table III presents the results of the first-stage regressions estimating the probability of forced turnover. In columns (1) and (2), we use as controls idiosyncratic returns, market-adjusted industry returns, firm size, Tobin's Q, and year dummies (which also capture the effect of market returns). As the analysis proceeds, we add further controls. Columns (3) and (4) add CEO tenure 
and indicators for CEO age and outsider status as well as controls for CEO incentives. Columns (5) and (6) add governance variables.

[Insert Table III approximately here]

Concerning the control variables, we find that, unsurprisingly, CEOs delivering poor idiosyncratic performance are more likely to be fired. We also find, as do Jenter and Kanaan (2011) and Kaplan and Minton (2012), that CEOs in poorly performing industries are more likely to be terminated. Older CEOs and those with longer tenure are fired less often. As expected, both the existence and the strength of equity-based incentives are negatively related to the probability of dismissal, consistent with the notion that these incentives induce the CEO to work harder. Turnover risk for chairman-CEOs is significantly lower than for their non-chairman counterparts, and smaller boards fire more. Board independence and anti-takeover provisions are not robustly related to CEO dismissal.

Our main interest is in the candidate instrumental variables, shown at the top of the table. All these variables are highly statistically significant and correlated with forced turnover in the predicted direction. More volatile industries and those that have worse ratings fire their CEOs more.

Most of the existing work on determinants of dismissal does not control for firm or industry risk, and we believe our finding of a relationship between CEO turnover and the changeability of firm and industry conditions is novel and in itself interesting. ${ }^{13}$ It is also noteworthy that the impact of the instrumental variables is economically significant. For example, a 0.1 increase in industry volatility (which corresponds to about 1.2 standard deviations) is associated with an increase in the probability of dismissal of 1\%. Similarly, comparing CEOs of two otherwise equal firms, the $\mathrm{CEO}$ of the firm with an average industry rating of BBB has a turnover risk that is two percentage points higher than that of his colleague at a AAA rated industry. (Recall that ratings are scaled such that a unit increase in the rating variable corresponds to the difference between a $\mathrm{AAA}$ and a BBB rating.) We also include industry-adjusted firm-level volatility and rating because this allows us to only use the industry component of total risk as an instrument 
while retaining the firm-specific component as a potential determinant of compensation in the second stage. (The results do not depend on including the firm-specific excess risk variables.) As shown at the bottom of Table III, the interquartile range of predicted turnover rates in our base model is between 0.025 and $0.03 .^{14}$

In sum, we find that indeed CEOs who are exposed to higher ex-ante risk in industry conditions are more likely to be dismissed. The strong correlation between risk and CEO turnover establishes the relevance of the instruments and alleviates weak instrument concerns.

\section{B. Turnover Risk and CEO Pay: Main Results}

A first set of second-stage regressions is shown in Table IV. These regressions are an important starting point for understanding the main results, shown in Table V, which address several potential concerns with these baseline regressions.

The six columns of Table IV use the predicted turnover probabilities from Table III as the key explanatory variable for log total compensation. Each column uses the instrument shown at the bottom of the table. As can be seen from the $F$-statistic, shown in the last row of the table, all first stages are strong. The $F$-statistic are well above the threshold level of 10 suggested by Stock, Wright, and Yogo (2002).

Consistent with the central hypothesis, dismissal risk is strongly and positively associated with compensation in all six regressions.

The results also show that there are two countervailing effects of a high total exposure of a firm to changing conditions: First, the industry component of total firm risk drives up compensation through increasing dismissal risk. Second, higher firm-specific volatility and worse firm-specific ratings, relative to the industry, tend to imply lower compensation, perhaps because these firms cannot afford to pay high compensation, or because this indicates low CEO skill.

The results further suggest that turnover risk driven by industry ratings is compensated more strongly than turnover risk driven by industry volatility. This also holds when we set all missing ratings to the mean of their industry (see the Internet Appendix).

[Table IV approximately here] 
It is possible that part of the result shown in Table IV is due to compensation for the riskiness of equity-based pay. To alleviate this concern, we use subjective values of compensation as the dependent variable. With this measure, we directly adjust the value of compensation to take into account differences in pay structure.

The results are shown in Table V. The main finding is that dismissal risk remains a statistically and economically significant determinant of CEO compensation.

[Table V approximately here]

Moreover, in both Table IV and Table V, we include a range of control variables. As discussed in Section I, including CEO characteristics likely goes a long way in reducing an important endogeneity concern, a correlation of our instruments with skill and selection on skill. The former concern is alleviated also through the use of industry-level instruments. For the concern regarding selection, it could be argued that industries with high CEO turnover (due to an "up-orout-culture", say) weed out the less-skilled CEOs. Over time, the remaining CEOs will be more highly-skilled than average, thus deserving higher pay. Similarly, it is possible that only highlyskilled CEOs choose to work in such competitive environments. This would induce a spurious correlation between turnover and pay, driven in part by unobserved skill. We believe that the included variables CEO age, CEO tenure, and a dummy variable indicating whether the CEO has been appointed from outside, in addition to past idiosyncratic performance, capture unobserved skill to a significant extent. ${ }^{15}$

Next, the compensating wage differential may be partly driven by effort costs. If high volatility leads, at the same time, to higher turnover risk and to a higher level of equity-based compensation, and more equity-based compensation induces the CEO to exert more effort, the CEO might receive an effort premium on pay, which could partially explain our results. To mitigate this concern, we include a control for whether the CEO receives equity-based compensation as well as the dollar incentives of the CEO. As expected, both incentive variables have a positive secondstage coefficient, consistent with the idea that equity-based incentives induce the CEO to work hard, earning him higher compensation. Importantly for our analysis, these controls pick up the 
effect that industry risk may have on compensation through the granting of incentives. Indeed, the second-stage coefficients on turnover risk decrease as we move from columns (1) and (2) to columns (3) and (4), but they remain highly significant. Based on these results, we conclude that the effect of turnover risk (driven by industry risk) on compensation is unlikely to only reflect compensation for effort cost.

Finally, regressions (5) and (6) also include governance characteristics. The second-stage coefficients of turnover risk increase compared to the previous regressions. This indicates that, if anything, omitting governance variables induces a bias against finding a significant turnover risk premium.

\section{Quantitative Interpretation}

Is the size of the coefficients we obtain in these regressions reasonable? To answer this question, we begin by observing that the coefficients vary somewhat across the instruments we use. In columns (3) and (5) of Table V, which use volatility as the instrument, they are $5.6 \%$ and $9.7 \%$, respectively. Similar quantitative results hold for semi-volatility (see the Internet Appendix). The coefficients are sometimes substantially higher when the rating is the instrument. However, ratings data are available only for a smaller subset of firms, and the first-stage F-statistic tends to be lower for ratings than for the other instruments. Therefore, while, economically, ratings are a powerful and intuitive predictor of dismissal risk, for the quantitative interpretation we primarily draw on the results using volatility as the instrument. ${ }^{16}$

Overall, then, a plausible estimate of the average dismissal risk premium is $7 \%$. We can compare these quantities with theoretical predictions from a simple life-cycle model reflecting career concerns that we develop in Internet Appendix B. There, we find that for realistic parameter values, the cash equivalent of CEO pay needs to rise by $3.5 \%$ to $10 \%$ to compensate the CEO for one percentage point of dismissal risk. Therefore, our estimates of the size of the turnover risk premium are in the range of reasonable theoretical calibrations.

Translating the elasticities into dollar values implies that in the cross section, a one percentage point increase in turnover risk is compensated with about $\$ 120,000(\approx \$ 1.7 \mathrm{~m} \times 7 \%)$ in subjective 
value for the median CEO, and with around $\$ 220,000(\approx \$ 3.2 \mathrm{~m} \times 7 \%)$ for the CEO receiving mean pay.

According to the full specifications of Table III, the standard deviation of the predicted turnover probability is around 0.025 . Therefore, a one standard deviation increase in the predicted turnover probability implies a $19 \%(=\exp (7 \times 0.025)-1)$ increase in total compensation. By comparison, the standard deviation of log total assets, one of the primary determinants of CEO compensation, is 1.76, and the regression coefficient of $\log$ assets is around 0.3. Therefore, a one standard deviation increase in log total assets implies a $70 \%(=\exp (0.3 \times 1.76)-1)$ increase in total compensation. Thus, the cross-sectional variation in turnover risk explains about a quarter to a third of the variation in the subjective value of total compensation that is explained by firm size.

While it is tempting to use these results to infer how much of the increase of CEO pay over time can explained by the rise in turnover risk, we caution that our identification strategy is restricted to the cross section. We simply note that aggregate developments in industry risk over the past decades are consistent with the pattern in CEO pay levels and turnover over time. This is reassuring.

\section{Severance Agreements}

In this section, we investigate the possibility that severance agreements mitigate the need for a turnover risk premium in flow compensation. This idea is a natural corollary of the central hypothesis of the paper: In a competitive labor market, only uninsured job risk should lead to a dismissal risk premium.

Thus, our goal is to analyze how the interaction between turnover risk and severance affects flow compensation. We use data on contractual severance agreements for the time period 2006 to 2009. In this time period, around one third of CEOs had no severance agreement. Among those that did have such an agreement, the average contracted amount of severance is about two times total yearly compensation. ${ }^{17}$

As a starting point, we assume the existence of a severance agreement to be exogenous and include the (predicted) interaction of the forced turnover and severance dummies in the second 
stage. This regression yields a generally insignificant interaction term.

However, the existence of a severance agreement is likely endogenous, and this may bias these results. If, for instance, CEOs who obtain severance agreements are on average more powerful than other CEOs, they may also be able to extract higher flow compensation for a given turnover risk than their less powerful counterparts, thereby counteracting the insurance effect of severance. Therefore, we instrument the existence of severance agreements. Analogously to our industrylevel instruments for turnover risk, we use the relative prevalence of severance agreements in the industry as an instrument for the existence of a severance agreement on the firm level. The idea is that the extent to which colleagues of the CEO in the same industry have severance agreements has an impact, through benchmarking and word of mouth, on the probability that a given CEO receives a severance agreement, too. Because interaction terms of two endogenous variables are difficult to analyze in a 2SLS setting, in this analysis, we focus on reduced form regressions. These regressions link executive compensation directly to instruments for turnover risk, the existence of a severance agreement, and their interaction.

We begin by presenting, in column (1) of Table VI, the reduced form equivalent of the 2SLS regression of column (1), Table V. Consistent with the 2SLS results, industry volatility is strongly associated with subjective values of compensation. (The same is true for industry semi-volatility and industry rating. $)^{18}$

Next, we verify that the frequency of severance agreements in the industry is a strong predictor (and instrument) for the existence of a severance agreement at the firm level. Column (2) of Table VI strongly supports this hypothesis. In industries where severance agreements are less frequent than in the full sample (the "LowSev" industries), CEOs are about $10 \%$ less likely to have a severance agreement. The results are robust to a range of cutoffs in defining "LowSev" industries.

The regressions in columns (3)-(8) then interact the LowSev indicator with the instrumental variables for forced turnover. We predict that in industries where severance agreements are rare - implying that a CEO is unlikely to have a severance agreement - industry risk would be more strongly compensated through flow compensation. 
The results in Table VI provide confirmatory evidence. For example, column (7), which includes the full set of controls, implies that a 0.01 increase in volatility is associated with about $0.48 \%$ higher compensation in industries where severance agreements are common, but with about $1.13 \%(=0.48+0.65)$ higher compensation in industries where severance agreements are rare. In this specification, a 0.01 increase in industry volatility is associated with about $0.1 \%$ higher dismissal probability. This implies that the turnover risk premium in industries where severance agreements are rare is about $11.3 \%$, but only $4.8 \%$ where severance agreements are common.

Overall, these findings are consistent with the notion that uninsured job risk leads to a higher dismissal risk premium than job risk that is to some extent insured.

[Table VI approximately here]

\section{E. Robustness}

First, we consider a broad range of parameter values when calculating subjective compensation values. The two most important of these are CEO risk aversion and the portfolio constraint CEOs face. We vary the coefficient of relative risk aversion between 1 and 5 , and we vary the percentage of equity that CEOs are required to hold (in excess of what they would optimally hold) between $20 \%$ and $80 \%$. As discussed above in Section III.B, the estimated turnover risk premium decreases when going from unadjusted compensation (Table IV) to risk-adjusted compensation (Table V). This suggests that pay structure confounds the estimated risk premium to some extent when using market values of compensation. Continuing this logic, we expect the estimated turnover risk premium to decrease (increase) as we increase (decrease) CEO risk aversion and the portfolio constraint CEOs face. This is indeed what we find in Table VII. (The table only provides the second-stage estimates for the key coefficient of interest. The first stages are not affected by the parameter choice for the second-stage dependent variable.) We generally find an economically and statistically significant turnover risk premium throughout these parameter variations, mitigating the concern that compensation for differences in pay structure is the primary driver of our results. ${ }^{19}$

[Table VII approximately here] 
Second, it is possible that the increasing incidence of forced CEO turnovers identified through press reports is due to an increase in CEO turnover coverage, and it is also conceivable that the press follows particular types of firms more than others. In either case, our results may be biased. Therefore, we repeat our analysis using the age-based turnover classification described in Section II Table VIII summarizes the results, showing only the second-stage coefficients and $t$-statistics of predicted turnover probabilities for the respective turnover classification as well as the first-stage $F$-statistic. As can be seen, the first stage is again highly significant for most regressions. The second-stage coefficients are overall similar to those obtained with the primary classification. We can also investigate an additional conjecture. At lower age cutoffs, the second-stage coefficient should be higher than at higher age cutoffs. This is because CEOs leaving at, for example, age 50, are more likely than CEOs leaving at age 60 to have been dismissed than to have departed voluntarily. This is what we find in those areas of the table where all first stages are strong.

[Table VIII approximately here]

Third, we examine whether particular forms of flow compensation are used to compensate for job risk. Base salaries exhibit little variation across CEOs in this sample; nonetheless, we find that the regressions equivalent to those shown in Tables IV and V mostly yield a statistically significant (though economically small) relationship between turnover risk and salaries. We also find the same for salaries and bonuses combined.

Fourth, we examine whether mis-estimation of option compensation could bias our results. Historically, firms were allowed to expense stock options at their intrinsic value (which, given that most options were granted at the money, would often resulted in zero option expenses). This appears to have been an important factor in explaining the development of executive compensation levels (Hall and Murphy, 2003; Murphy, 2013). Indeed, this factor may also be relevant for our analysis. If firms in volatile industries were granting disproportionately more options due to mis-estimation than firms in safer industries, the estimated turnover risk premium may be biased. However, the favorable accounting treatment of stock options was effectively eliminated when FAS 123R was implemented in 2005. We find that our main results hold in the period 
2006 to 2009, too. On this smaller sample, we obtain second-stage coefficients that are between one half and two thirds of the full-sample estimates; they remain economically and statistically significant.

Finally, the results are also robust to a large variety of alternative specifications and subsamples. Among other things, the results continue to hold (1) if we include various other controls, such as the general ability index of Custódio, Ferreira, and Matos (2013) or the percentage of shares held by blockholders, (2) if we use the market value of the firm as a measure of firm size, (3) if we exclude CEOs with ownership in excess of $10 \%$ of common shares, (4) if we exclude CEOs in the highest and lowest percentile of the pay distribution (or winsorize compensation at that level), (5) if we separately exclude the High Tech sector (which exhibits the highest turnover rate), the Finance sector, or Utilities from the regressions, (6) if we exclude firms in default or selective default, and (7) if we use two-way clustered standard errors, thus allowing for cross-sectional interdependencies.

\section{Conclusion and Interpretation}

This paper makes the simple point that forced turnover risk explains an important part of the cross-sectional variation of compensation for the CEOs of public U.S. corporations. The empirical magnitude of the turnover risk premium - about $7 \%$ greater subjective compensation for a one percentage point increase in turnover risk - is in line with calibrated theoretical predictions.

Using subjective compensation values mitigates the concern that our results are driven by the riskiness of equity-based pay; controlling for CEO incentives reduces the likelihood that the results arise due to compensation for effort cost; including a range of other controls such as governance measures limits the concern that other omitted variables are biasing the results; and analyzing the post-FAS 123R period suggests that a turnover risk premium continues to exist even in times when the mis-estimation of the opportunity cost of stock options was unlikely to play an important role. Nonetheless, we emphasize that we cannot completely exclude the possibility that these four factors (or others that we did not explicitly address) partially explain the results.

Keeping in mind these limitations, the relevance of these findings is two-fold. First, by doc- 
umenting that higher job risk is compensated with higher CEO pay in the cross section, this paper complements the argument brought forward by Kaplan and Minton (2012) that part of the aggregate time series development of executive pay can be explained by decreasing CEO tenures.

Second, the cross-sectional evidence is important because it speaks to a central issue in the debate on executive compensation. Some argue that CEO pay is largely determined by market forces; see, for example Kaplan (2008). Others argue that CEOs may be entrenched and may be able to set their own pay and job security; this argument has been most forcefully made by Bebchuk and Fried (2004). To understand how our findings contribute to this debate, consider the setting of partially entrenched CEOs. For each individual CEO, there will be a positive association between turnover risk and compensation. To see this, assume that the CEO prefers high compensation and low turnover risk. However, the CEO is unlikely to be free in choosing any combination of turnover risk and compensation; instead, he needs to expend his political capital in the firm to achieve his goals. It is natural to assume, therefore, that he faces an entrenchment constraint: Increasing compensation requires him to also accept a higher probability of getting fired, perhaps because he is now held more accountable. That is, as long as job security and compensation are not perfect substitutes, the CEO chooses from a menu of turnover risk compensation pairs which reflect the tradeoff between the two as well as his level of entrenchment.

However, as we move from the individual CEO to the cross section of CEOs with varying degrees of entrenchment, we obtain different predictions: Each CEO will aim to choose his optimal combination of compensation and job security, but the more entrenched CEOs will obtain more of both. This follows from a standard microeconomic argument by which an agent with greater income will consume more of all (normal) goods. Therefore, under partial entrenchment, we would expect to observe a negative correlation between turnover probabilities and compensation in the cross section of CEOs. The evidence we have presented would appear to be largely inconsistent with this notion.

It is clear that some CEOs do achieve spectacular compensation packages while at the same time being apparently immune against the risk of being fired. But precisely in light of these cases of egregious abuse of power and failing corporate governance, it is reassuring that, with respect to 
the relationship between pay and turnover risk, the available evidence suggests that, on average, the market for CEOs works in a way that is consistent with a model of competitive pay. 


\section{Notes}

${ }^{1}$ We use the terms "dismissal risk," "job risk," and "turnover risk" interchangeably.

${ }^{2}$ We discuss the role of severance agreements in Section III.D.

${ }^{3}$ Eisfeldt and Rampini (2008) document a correlation of aggregate, realized levels of M\&A related turnover and compensation with the business cycle to motivate a theoretical model of optimal incentives. Using a cross section of firms, Agrawal and Knoeber (1998) find that managers under a higher threat of takeover earn more, arguably because they need to be compensated for the risk of losing deferred compensation and firm-specific human capital. Our results contrast with those of Hayes, Hillegeist, and Keating (2005) who find a negative association between financial distress risk and compensation.

${ }^{4}$ Besides the econometric difficulties of proving evidence of causality in the time series, there are also theoretical concerns. Outside options, which determine CEOs' reservation utilities, decline when turnover risk increases over time across all firms. Thus, from a theoretical perspective, turnover risk and pay need not be correlated over time even if CEOs' participation constraints are always binding. See also Edmans and Gabaix (2011).

${ }^{5}$ Studies in labor economics that investigate wage differentials that compensate for the risk of unemployment include Li (1986), Heywood (1989), and Moretti (2000).

${ }^{6}$ Other papers investigating subjective compensation values include Lambert, Larcker, and Verrecchia (1991), Carpenter (1998), Meulbroek (2001), and Conyon, Core, and Guay (2011), among others.

${ }^{7}$ Higher market values of compensation in riskier firms might also be driven by a mechanical relationship in that Black-Scholes values are strictly increasing in the volatility of the underlying stock. We address this concern by constructing a third compensation measure, volatility-adjusted compensation, that replaces the Black-Scholes values of option packages reported in ExecuComp 
by our own calculations of Black-Scholes values using the same constant volatility parameter for all CEOs and all years (and keeping all the other parameters as in ExecuComp). The value of option packages computed in this way still varies along many other dimensions, in particular the number of options granted. Our results are robust to this alternative compensation measure and are available in the Internet Appendix.

${ }^{8}$ The classification requires significant data collection efforts, and we are thus grateful to Cristian Dezsö, Dirk Jenter, Greg Nini, Bob Parrino, and Luke Taylor for providing us with their data. The methodology is as follows. Departures for which the press reports state that the CEO was fired, forced out, or retires or resigns due to policy differences or pressure, are classified as forced. Turnovers of CEOs below the age of 60 which have not been classified as forced by the press criterion, are classified as forced if the articles do not report the reason to be death, poor health, or acceptance of another position or the articles report that the CEO is retiring but the company does not announce the retirement date at least 6 months before departure. For further details, see Parrino (1997).

${ }^{9}$ Many CEOs hold company stock and options in excess of what they are constrained to hold by vesting restrictions. To the extent that such decisions are driven by low risk aversion and/or excess confidence or optimism, the true subjective values of compensation would be higher than predicted by the cited models, and hence our empirical results would be stronger.

${ }^{10}$ We also compute the semi-volatility over the same horizon. This risk measure only takes into account return realizations that are below the mean. High values therefore reflect left-skewness of the return distribution, or downside risk. We report all results based on this risk measure in the Internet Appendix.

${ }^{11}$ SOX became effective on July 30, 2002. NYSE and NASDAQ rules, requiring a majority of board members to be independent, became effective through SEC approval in November 2003. Absolute compliance was demanded by December 31, 2005. The RiskMetrics coding of who is an independent director is stricter than that of the exchanges. The results are not sensitive to the 
coding of the director independence variable.

${ }^{12}$ This modified index has a correlation of 0.79 with the original GIM-index on the 1993 to 2006 sample. The variables included in this modified index are blank check preferred, classified board, limit ability to call special meeting, limit ability to act by written consent, golden parachutes, limit ability to amend bylaws, limit ability to amend charter, cumulative voting, supermajority requirement, unequal voting rights, fair price, and poison pill.

${ }^{13}$ An exception is Bushman, Dai, and Wang (2010) who show that CEOs are more likely to be replaced when volatility of the idiosyncratic component of firm performance is high and less likely to be fired when exposure to market risk is high. Our focus is instead on the exposure to industry risk.

${ }^{14}$ The linear probability model, which is used to ensure consistency of the second-stage estimates, implies some negative predicted probabilities. For example, in column (1), 1,231 observations, or $5 \%$ of the sample, have a negative predicted dismissal probability. None of the observations have a predicted dismissal probability above one. In logit/probit regressions the economic effects of our instruments and other controls are similar, in magnitude and statistical significance, to the effects in the linear probability model.

${ }^{15}$ We also do not observe risk aversion of CEOs. If more risk-averse CEOs select into safe industries while risk-loving CEOs select into risky industries (which is conceivable given the evidence in Graham, Harvey, and Puri (2013) regarding matching of CEO and firm characteristics), this implies that risk premia would be decreasing in risk. To the extent that CEO age and CEO tenure capture risk-aversion, this selection concern is alleviated. Moreover, the regression coefficients can also be interpreted as weighted average derivatives of compensation with respect to turnover risk (Angrist and Krueger, 1999). More weight is placed on values near the median of the turnover risk distribution, and less on both tails. Thus, there is no obvious bias introduced by selection on unobserved risk aversion.

${ }^{16} \mathrm{~A}$ separate analysis reveals that the variation in ratings induces variation in turnover risk 
mostly in a particular region of ratings, namely in the region of relatively poor ratings; in the region of good ratings, turnover risk does not vary much with ratings. By contrast, the degree of variation in turnover risk that industry volatility explains is similar across the range of this instrument. (The same holds for semi-volatility.) In other words, the treatment intensity of the two instruments is different: that of ratings is more variable than that of volatility, leading to different implied average treatment effects (Angrist and Pischke, 2009).

${ }^{17}$ This is consistent with earlier studies (Dahiya and Yermack, 2008; Lys, Rusticus, and Sletten, 2010). Actual severance payments often have a discretionary component beyond contractually agreed amounts (Yermack, 2006).

${ }^{18}$ The results imply that a 0.01 increase in industry volatility is associated with $1.05 \%$ higher compensation on average. This is in line with the 2SLS results on this sample period: According to first-stage regressions, in this sample period and with the baseline specification, a 0.01 increase in volatility is associated with a $0.17 \%$ increase in turnover risk; according to the corresponding second-stage regressions, such a $0.17 \%$ increase in the turnover probability is in turn associated with an increase in compensation of about $1.05 \%$.

${ }^{19}$ Note that, in this exercise, we are setting CEO risk aversion to the same value for all CEOs and then vary this parameter value. Only if we had individual-level CEO data could we test the prediction that risk premia are increasing in CEO risk aversion. 


\section{References}

Abowd, John M., and Orley C. Ashenfelter, 1981, Anticipated unemployment, temporary layoffs, and compensating wage differentials, in Sherwin Rosen, ed.: Studies in Labor Markets (University of Chicago Press).

Agrawal, Anup, and Charles R. Knoeber, 1998, Managerial compensation and the threat of takeover, Journal of Financial Economics 47, 219-239.

Angrist, Joshua D., and Alan B. Krueger, 1999, Empirical strategies in labor economics, in Orley C. Ashenfelter, and David Card, ed.: Handbook of Labor Economics, vol. 3 (Elsevier).

— , 2001, Instrumental variables and the search for identification: From supply and demand to natural experiments, Journal of Economic Perspectives 15, 69-85.

Angrist, Joshua D., and Jörn-Steffen Pischke, 2009, Mostly Harmless Econometrics (Princeton University Press: Princeton).

Bebchuk, Lucian, and Jesse Fried, 2004, Pay without performance (Harvard University Press: Cambridge).

Bennedsen, M., K. Nielsen, F. Perez-Gonzalez, and D. Wolfenzon, 2007, Inside the family firm: The role of families in succession decisions and performance, Quarterly Journal of Economics $122,647-691$.

Bushman, Robert, Zhonglan Dai, and Xue Wang, 2010, Risk and CEO turnover, Journal of Financial Economics 96, 381-398. 
Cai, Jay, and Anand M. Vijh, 2005, Executive stock and option valuation in a two state-variable framework, Journal of Derivatives 12, 9-27.

Carpenter, Jennifer, 1998, The exercise and valuation of executive stock options, Journal of Financial Economics 48, 127-158.

Conyon, Martin J., John E. Core, and Wayne R. Guay, 2011, Are U.S. CEOs paid more than U.K. CEOs? Inferences from risk-adjusted pay, Review of Financial Studies 24, 402-438.

Core, John E., and Wayne R. Guay, 2002, Estimating the value of employee stock option portfolios and their sensitivities to price and volatility, Journal of Accounting Research 40, 613-629.

— , and David F. Larcker, 2011, The power of the pen and executive compensation, Journal of Financial Economics 88, 1-25.

Custódio, Cláudia, Miguel A. Ferreira, and Pedro Matos, 2013, Generalists versus specialists: Lifetime work experience and chief executive officer pay, Journal of Financial Economics 108, 471-492.

Dahiya, Sandeep, and David Yermack, 2008, You can't take it with you: Sunset provisions for equity compensation when managers retire, resign or die, Journal of Corporate Finance 14, 499-511.

Dai, Zhonglan, Li Jin, and Weining Zhang, 2012, CEO incentive dynamics and their effect on firm value, Working Paper.

Edmans, Alex, and Xavier Gabaix, 2011, The effect of risk on the CEO market, Review of Financial Studies 24, 2822-2863. 
Eisfeldt, Andrea L., and Camelia M. Kuhnen, 2013, CEO turnover in a competitive assignment framework, Journal of Financial Economics 109, 351-372.

Eisfeldt, Andrea L., and Adriano A. Rampini, 2008, Managerial incentives, capital reallocation, and the business cycle, Journal of Financial Economics 87, 177-199.

Fama, Eugene, and Kenneth French, 1997, Industry costs of equity, Journal of Financial Economics 43, 153-193.

Fee, C. Edward, and Charles J. Hadlock, 2004, Management turnover across the corporate hierarchy, Journal of Accounting and Economics 37, 3-38.

Frydman, Carola, 2005, Rising through the ranks: The evolution of the market for corporate executives, Working paper.

Gabaix, Xavier, and Augustin Landier, 2008, Why has CEO pay increased so much?, Quarterly Journal of Economics 123, 49-100.

Gompers, Paul A., Joy L. Ishii, and Andrew Metrick, 2003, Corporate governance and equity prices, Quarterly Journal of Economics 118, 107-155.

Graham, John, Campbell Harvey, and Manju Puri, 2013, Managerial attitudes and corporate actions, Journal of Financial Economics 109, 103-121.

Hall, Brian J., and Kevin J. Murphy, 2002, Stock options for undiversified executives, Journal of Accounting and Economics 33, 3-42.

— 2003, The trouble with stock options, Journal of Economic Perspectives 17, 49-70. 
Hartzell, Jay, Eli Ofek, and David Yermack, 2004, What's in it for me? Personal benefits obtained by CEOs whose firms are acquired, Review of Financial Studies 17, 37-61.

Hayes, Rachel M., Stephen A. Hillegeist, and Elizabeth K. Keating, 2005, Financial distress risk and initial CEO compensation contracts, Working paper.

Hayes, Rachel M., Michael Lemmon, and Mingming Qiu, 2012, Stock options and managerial incentives for risk taking: Evidence from FAS 123R, Journal of Financial Economics 105, 174-190.

Hermalin, Benjamin E., 2005, Trends in corporate governance, Journal of Finance 60, 2351-2384.

Heywood, John S., 1989, Do union members receive compensating differentials? The case of employment security, Journal of Labor Research 10, 271-85.

Ingersoll, Jonathan E., 2006, The subjective and objective evaluation of incentive stock options, The Journal of Business 79, 453-487.

Jenter, Dirk, and Fadi Kanaan, 2011, CEO turnover and relative performance evaluation, The Journal of Finance, forthcoming.

Kaplan, Steven N., 2008, Are U.S. CEOs overpaid?, Academy of Management Perspectives 22, $5-20$.

, and Bernadette A. Minton, 2012, How has CEO turnover changed?, International Review of Finance 12, 57-82.

Lambert, Richard, David F. Larcker, and Robert E. Verrecchia, 1991, Portfolio considerations in valuing executive compensation, Journal of Accounting Research 29, 129-149. 
Li, Elizabeth H., 1986, Compensating differentials for cyclical and noncyclical unemployment: The interaction between investors' and employees' risk aversion, Journal of Labor Economics 4, 277-300.

Lys, Thomas, Tjomme Rusticus, and Eva Sletten, 2010, Executive severance agreements, Working paper.

Meulbroek, Lisa K., 2001, The efficiency of equity-linked compensation: Understanding the full cost of awarding executive stock options, Financial Management 30, 530.

Moretti, Enrico, 2000, Do wages compensate for risk of unemployment? Parametric and semiparametric evidence from seasonal jobs, Journal of Risk and Uncertainty 20, 45-66.

Murphy, Kevin J., 2013, Executive compensation: Where we are, and how we got there, in George M. Constantinides, Milton Harris, and René M. Stulz, ed.: Handbook of the Economics of Finance (Elsevier).

— , and Jan Zaboinik, 2004, CEO pay and appointments: A market-based explanation for recent trends, American Economic Review 94, 192-196.

Oyer, Paul, 2008, The Making of an Investment Banker: Stock Market Shocks, Career Choice, and Lifetime Income, Journal of Finance 63, 2601-2628.

Parrino, Robert, 1997, CEO turnover and outside succession: A cross-sectional analysis, Journal of Financial Economics 46, 165-197.

Stock, James H., Jonathan H. Wright, and Motohiro Yogo, 2002, A survey of weak instruments and weak identification in generalized method of moments, Journal of the American Statistical Association 20, 518-529. 
Weisbach, Michael S., 1988, Outside directors and CEO turnover, Journal of Financial Economics 20, 431-460.

Yermack, David, 2006, Golden handshakes: Separation pay for retired and dismissed CEOs, Journal of Accounting and Economics 41, 237-256. 


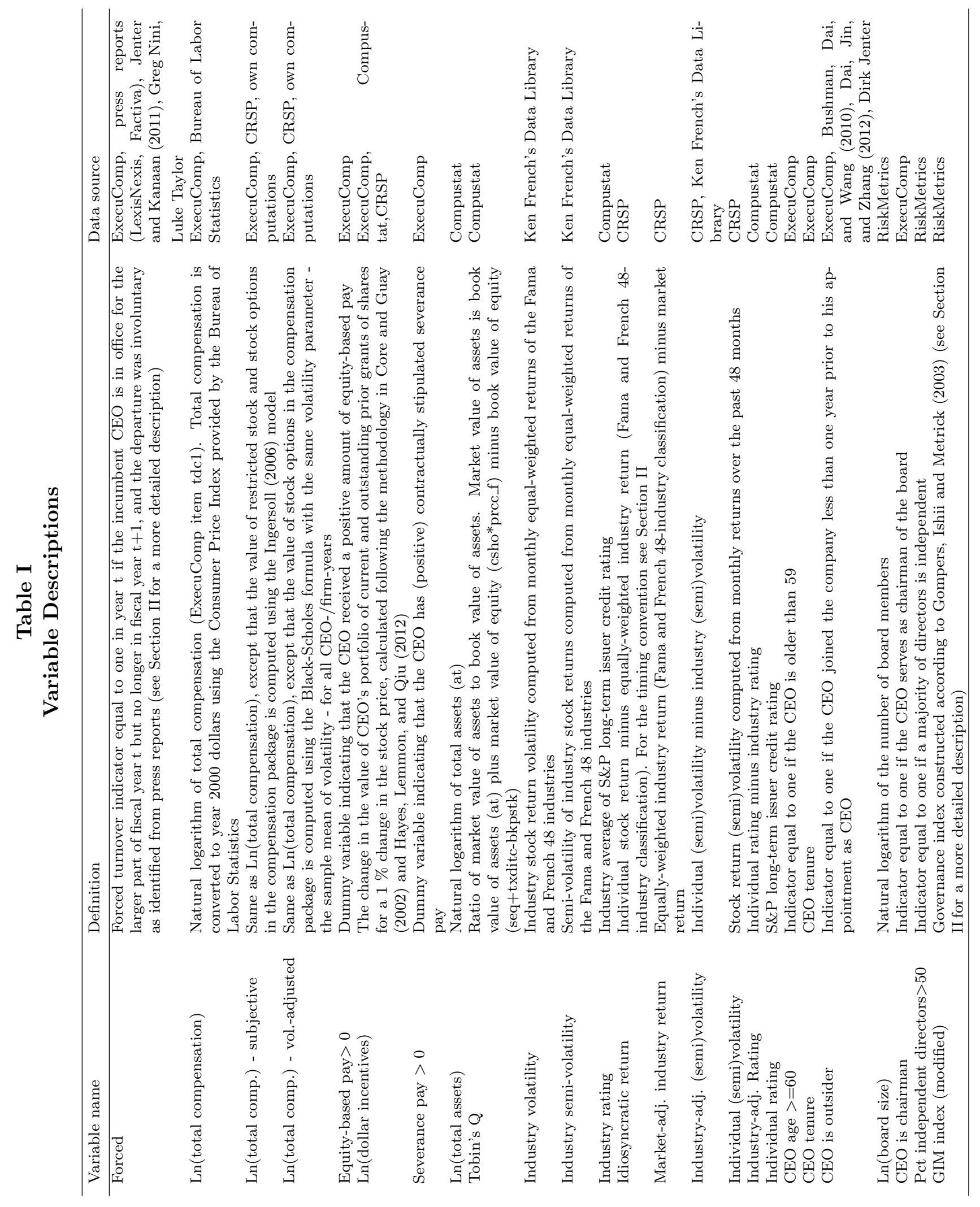


Table II

\section{Descriptive Statistics}

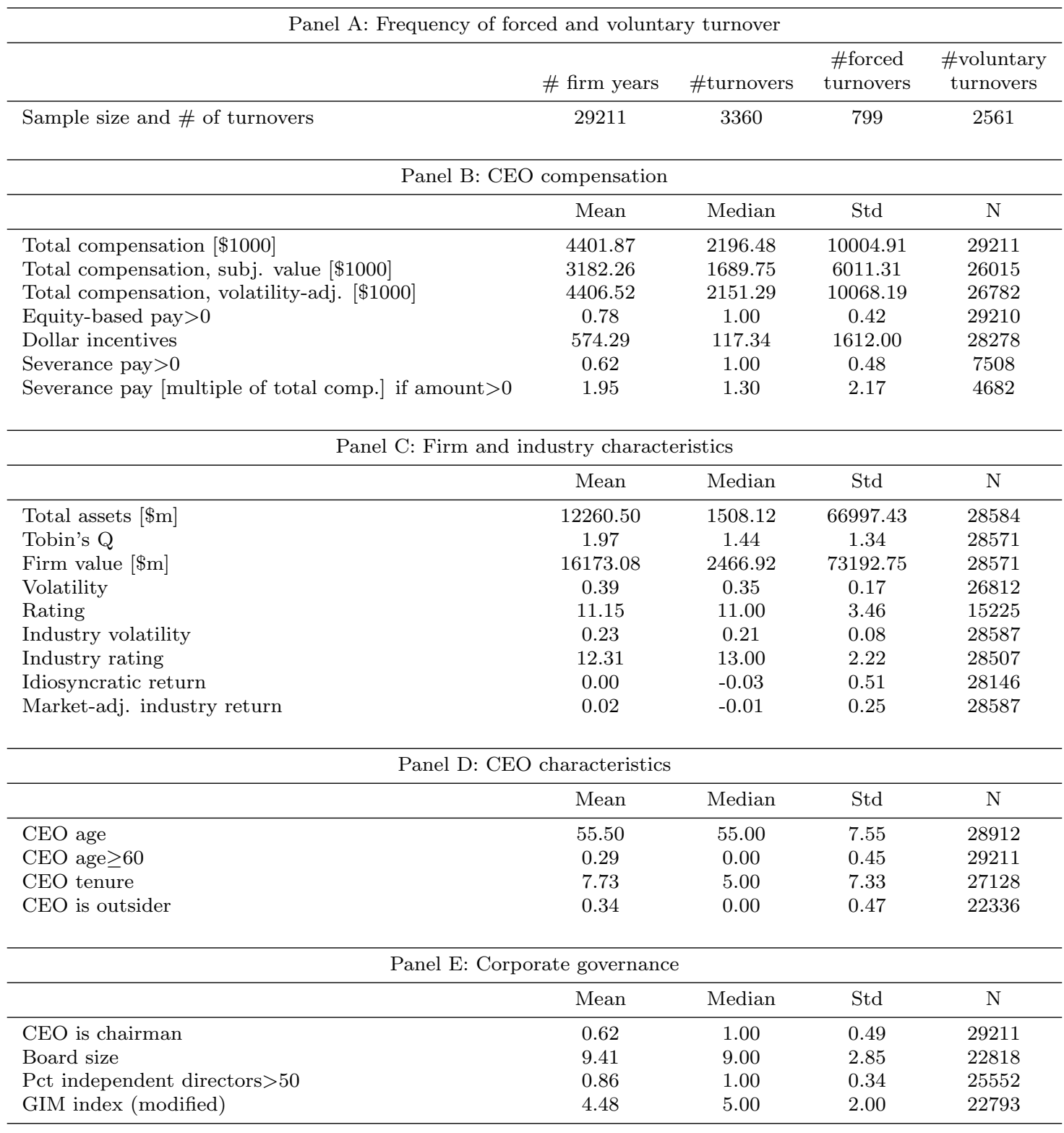




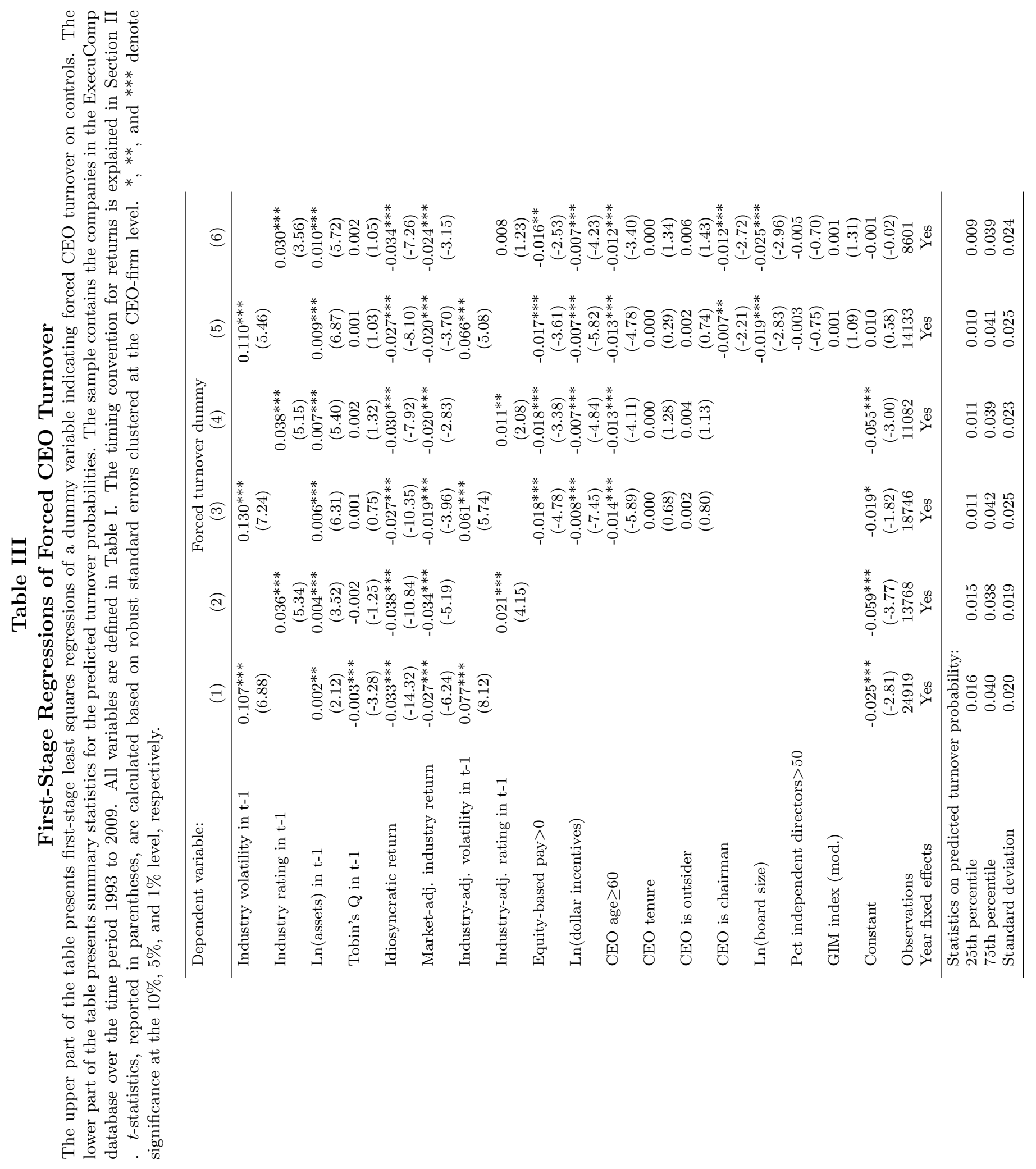




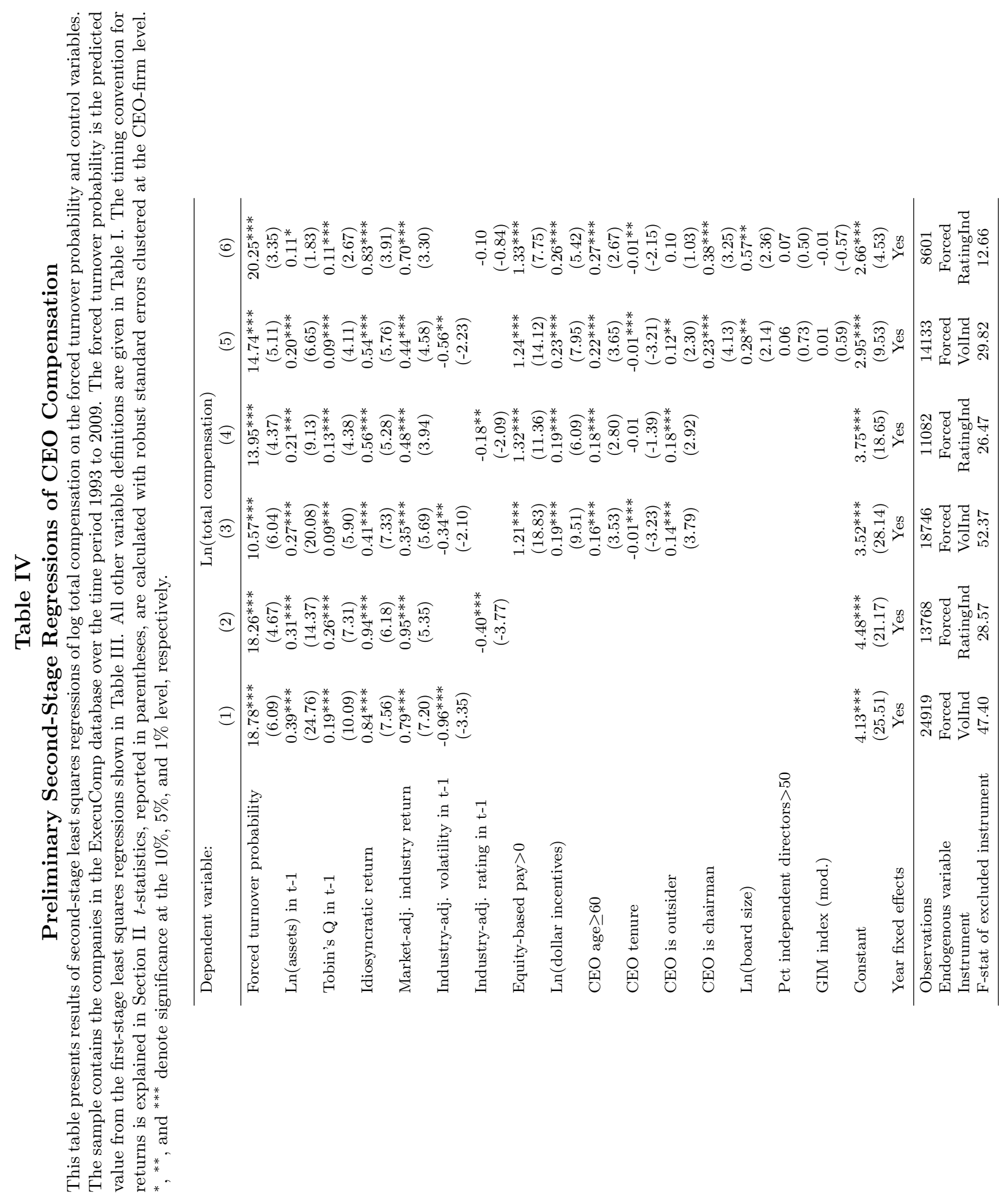




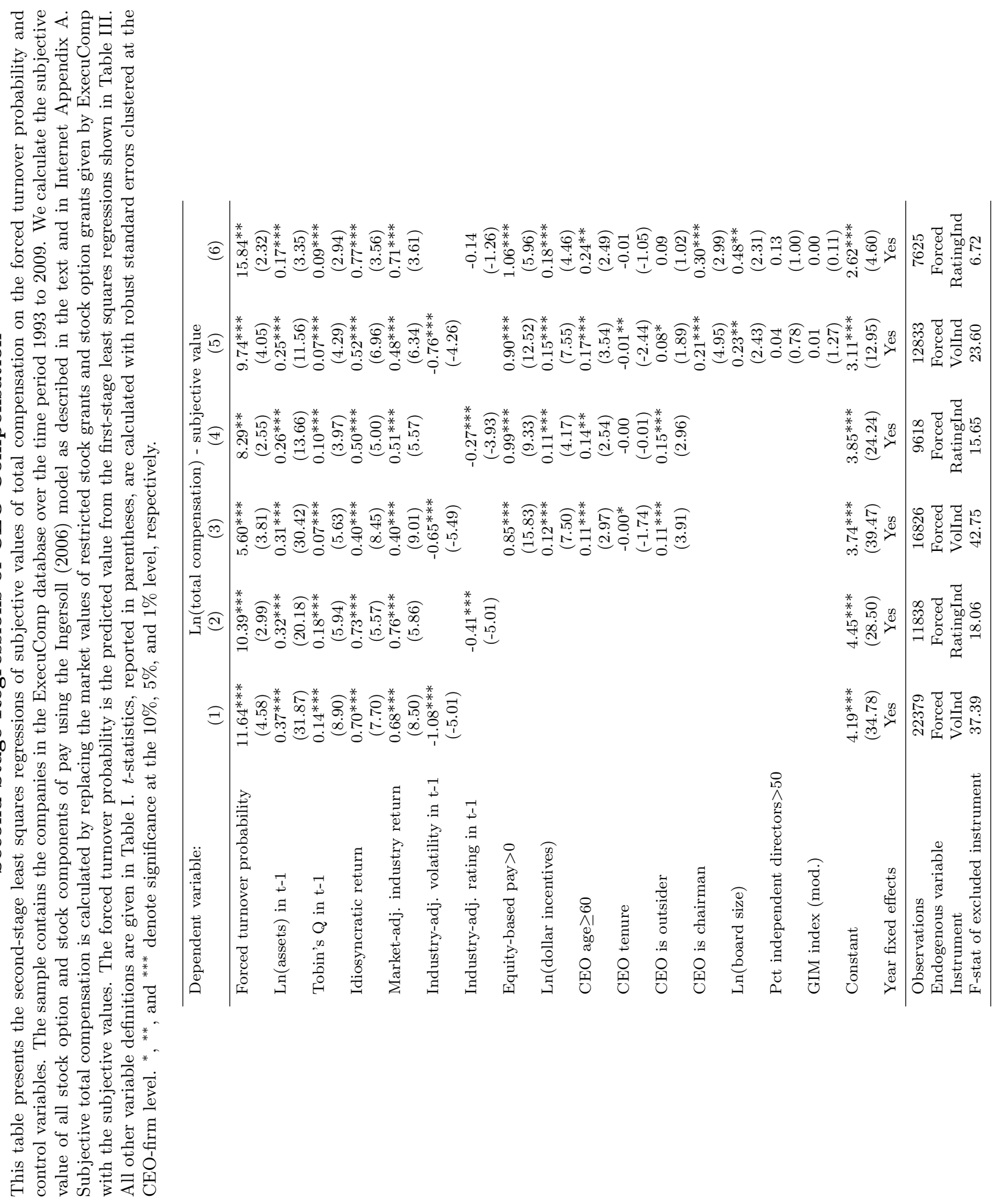




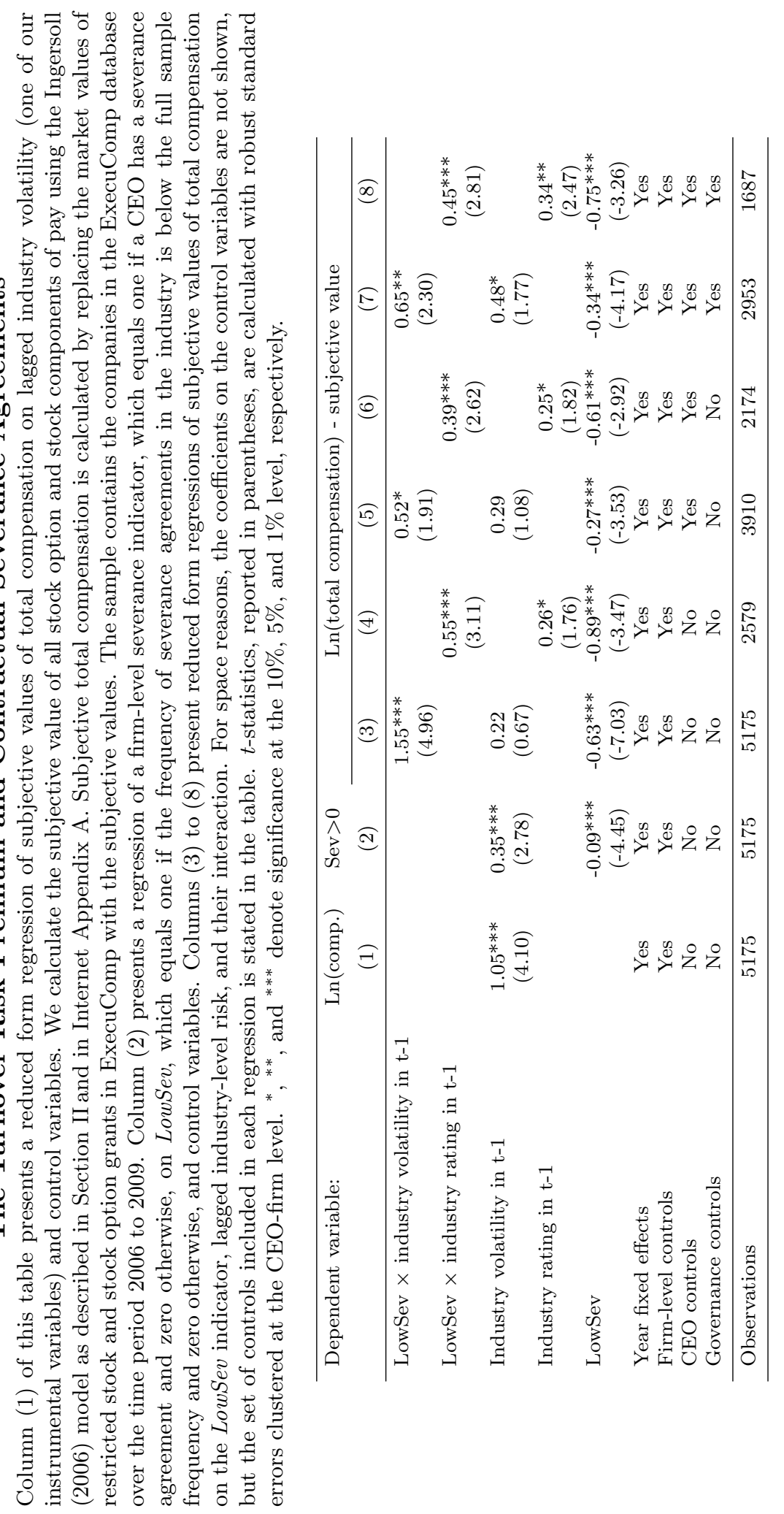




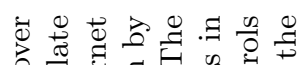

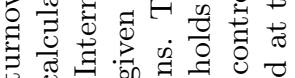

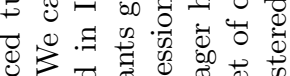

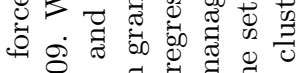

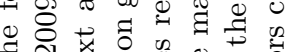

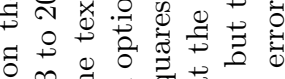

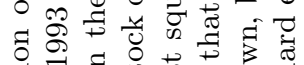

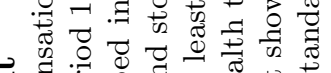

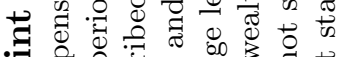
丞言 जी 0 :

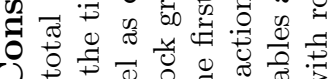

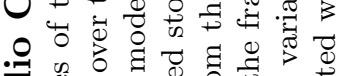

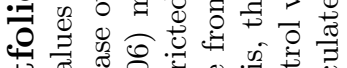

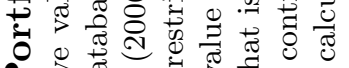

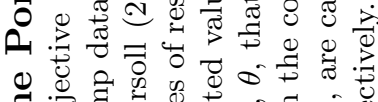

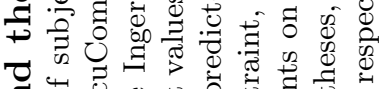

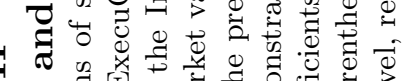

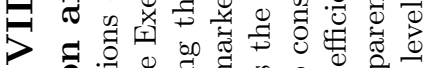

0.07 .000 సै

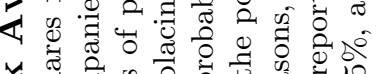

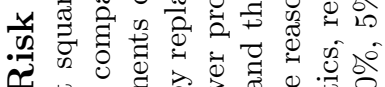

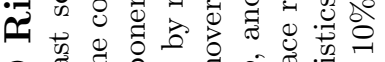

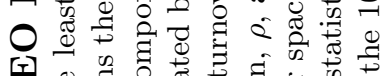

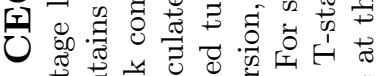

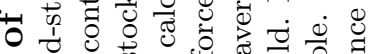

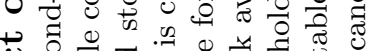

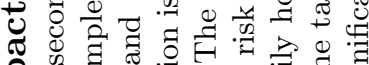

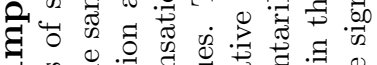
$\exists$ on

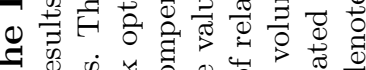
可

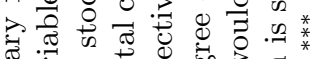

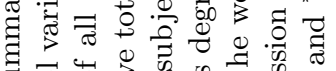

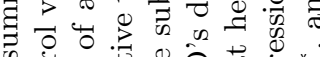

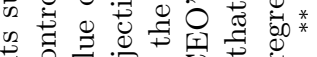

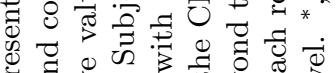

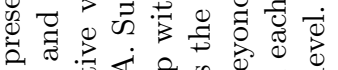

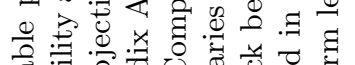

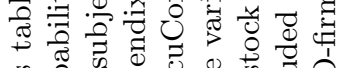
员

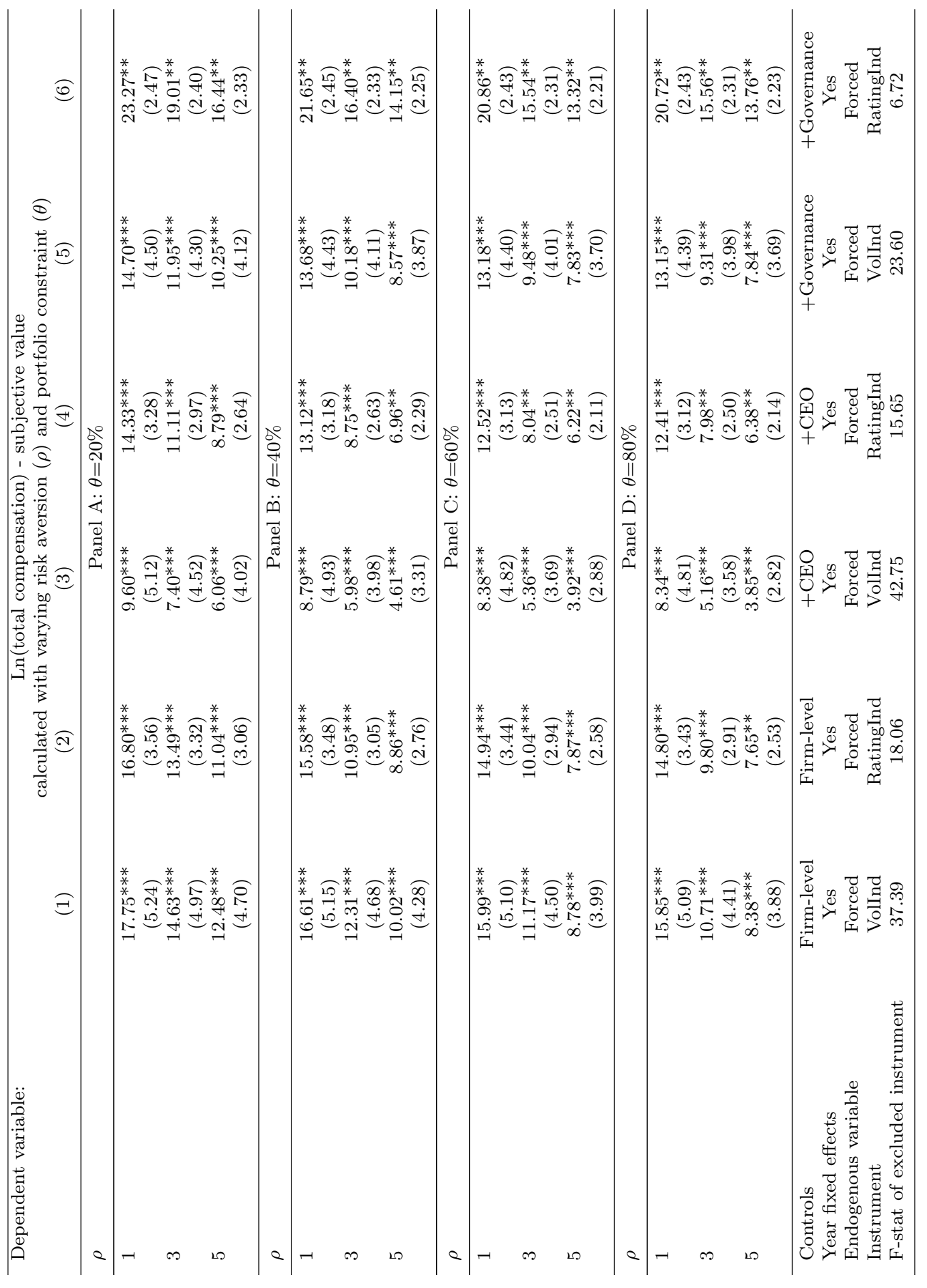




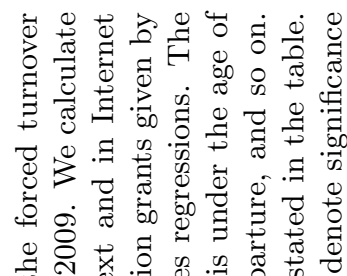

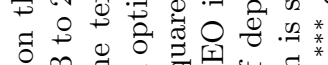

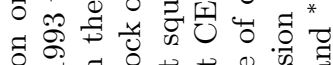

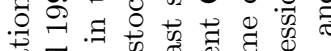

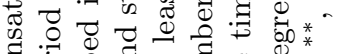

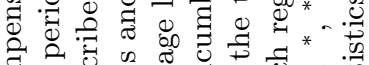

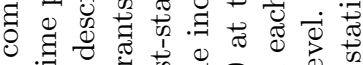

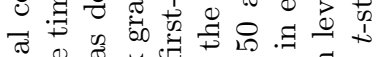

万人

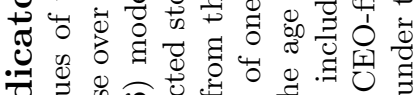

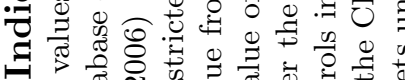

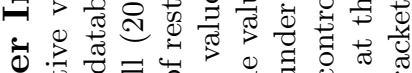

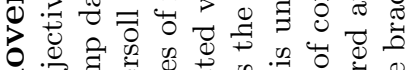

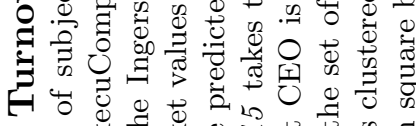

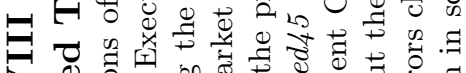

$>$ D

은

命

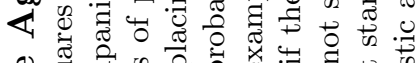

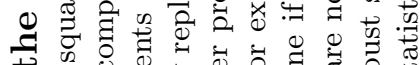

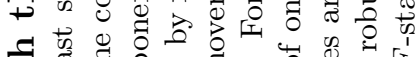

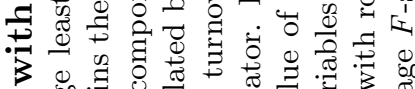

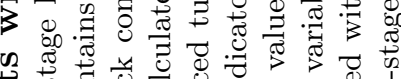

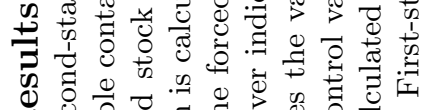

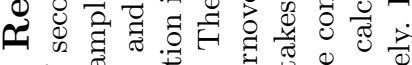

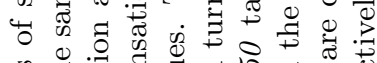

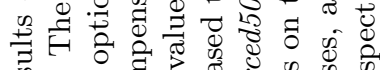
फु

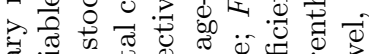

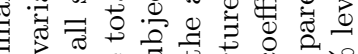

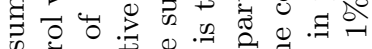

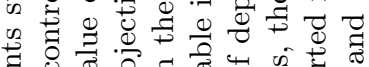
항

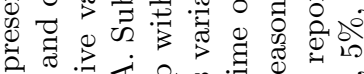

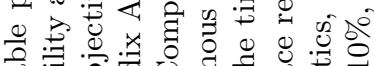

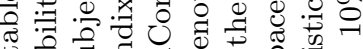
I

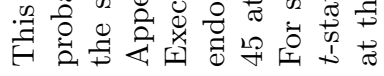

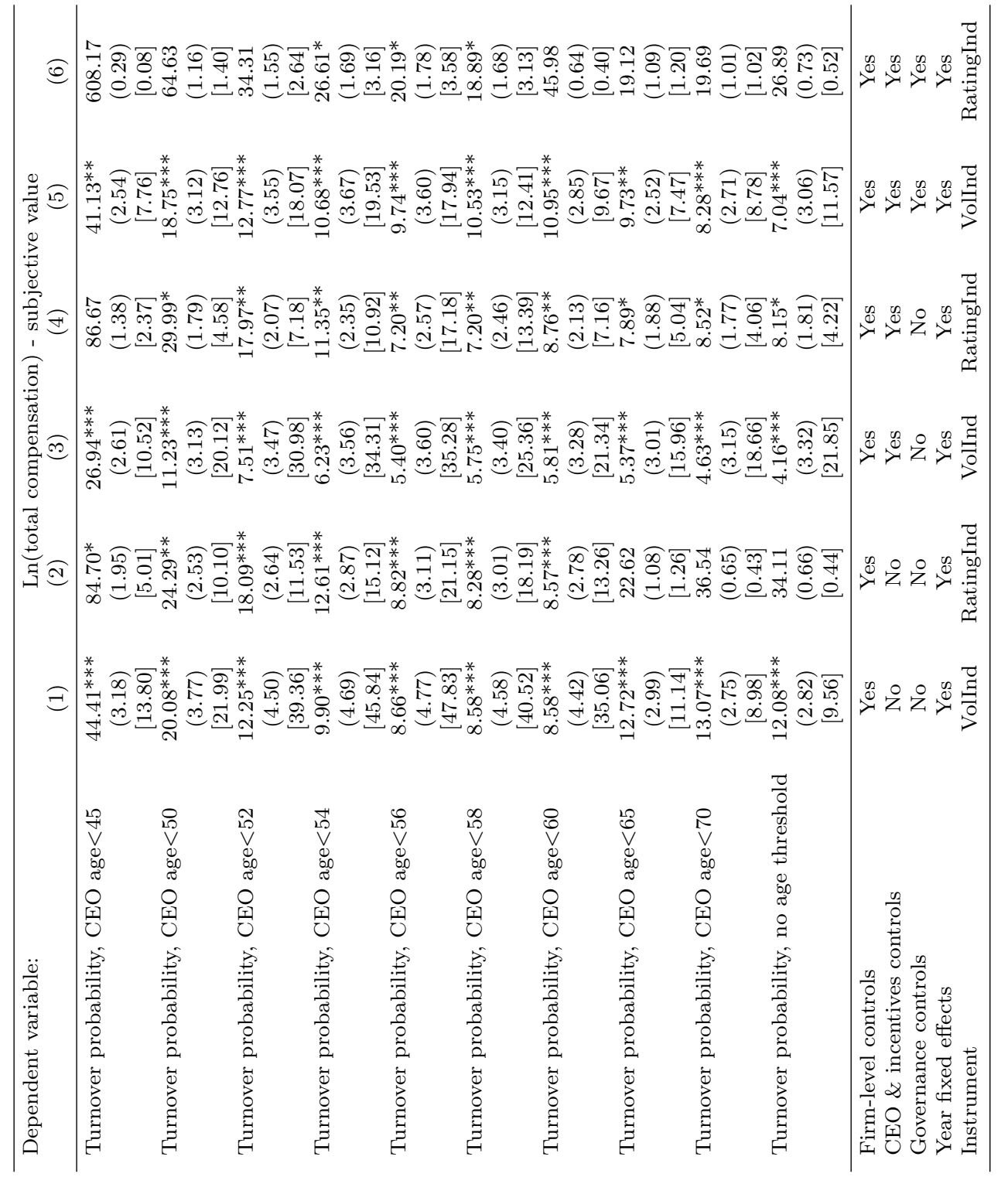




\title{
Internet Appendix for
}

\section{The Executive Turnover Risk Premium}

\author{
Florian S. Peters and Alexander F. Wagner*
}

${ }^{*}$ Citation format: Peters, Florian S. and Alexander F. Wagner, 2013, Internet Appendix to The Executive Turnover Risk Premium, Journal of Finance [DOI STRING]. Please note: Wiley-Blackwell is not responsible for the content or functionality of any supporting information supplied by the authors. Any queries (other than missing material) should be directed to the authors of the article. 
This Internet Appendix consists of three sections. Section A describes the Ingersoll (2006) model and its implementation. Section B presents a simple model of lifetime utility which we use to calibrate risk premia that can be attributed to uncertainty about future labor income. Section C provides additional tables that supplement the analysis in the main paper.

\section{A . Calculations of Subjective Values of Compensation}

In this section, we summarize the key equations needed to compute subjective values of compensation according to the Ingersoll (2006) model, and we describe the implementation. We verify that we replicate exactly the numerical examples provided in the original paper. ${ }^{1}$ A Stata program implementing this model is available from the authors' websites.

\section{A.1. Subjective Values of Restricted Stock Grants}

Section II, equation (11) of Ingersoll (2006) shows that the subjective value of a share restricted until time $T_{S}$, paying dividends continuously is ${ }^{2}$

$$
\hat{S}(S, T)=S\left[\frac{q}{\hat{q}}+e^{-\hat{q} T_{S}}\left(1-\frac{q}{\hat{q}}\right)\right]
$$

where $\hat{q}$ is the subjectively adjusted dividend yield derived by Ingersoll (2006). It equals $\hat{q}=$ $q+\rho(1-\theta) \theta v^{2}$. The following primitives appear in this equation:

1. $S$ is the share price at grant date.

2. $q$ is the dividend yield. We use ExecuComp item bs_div for 1993 to 2005 . From 2006 onwards, ExecuComp no longer provides dividend yields. For these years, we compute the

\footnotetext{
${ }^{1}$ For completeness, we note a few typos in the published version of Ingersoll (2006). In equation (12) in the second line, $\hat{q}$ and $\hat{r}$ should appear instead of $q$ and $r$. In the second to last line of Equation (B2), the second term in the curly parenthesis should read $\Phi\left(h_{k}^{-}\right)$instead of $\Phi\left(h_{k}^{+}\right)$. The caption of Table 4 should read $q=1 \%$ instead of $q=0 \%$ (see also p. 470 , bottom). These typos are apparent by comparing the published version with the working paper version. Also, only the corrected version yields the results in the tables presented in Ingersoll (2006). In our presentation here, we show the corrected formulas.

${ }^{2}$ In what follows, we set current time $t$ equal to 0 for convenience, and we, therefore, omit this additional argument.
} 
dividend yield from Compustat as an average over the previous four years.

3. $\rho$ is the coefficient of relative risk aversion. (Ingersoll uses the terminology $1-\gamma$ for relative risk aversion.) We comment on the choice of this parameter in the main text.

4. $\theta$ is the portfolio constraint, that is, the fraction of wealth that the manager is forced to hold in his firm's stock beyond what he would voluntarily hold. We comment on the choice of this parameter in the main text.

5. $v^{2}$ is the residual variance of the stock. Total stock variance is $\sigma^{2}$, decomposed as $\sigma^{2}=$ $v^{2}+\beta^{2} \sigma_{M}^{2}$, where $\beta$ is the CAPM- $\beta$ of the stock and $\sigma_{M}^{2}$ is the variance of the market return. We calculate the variances and estimate the CAPM- $\beta$ using monthly stock and market returns on 4-year rolling windows.

6. $T_{S}$ is the vesting period for the restricted stock grant. We assume $T_{S}=3$ years.

Thus, the subjective value of an entire restricted stock grant is

$$
N_{S} S\left[\frac{q}{\hat{q}}+e^{-\hat{q} T_{S}}\left(1-\frac{q}{\hat{q}}\right)\right]
$$

where $N_{S}$ is the number of shares granted. We use ExecuComp item rstkgrnt, the market value of the share grant, for $N_{S} S$.

\section{A.2. Subjective Values of Stock Option Grants}

Section IV of Ingersoll (2006) discusses the subjective valuation of stock options with optimal exercise by the executive. While for the European stock option case a closed form is available for subjective option values (see equation (12)), a numerical approach is needed to optimize the exercise time. Ingersoll (1998) developed the barrier derivative approach to pricing American options, and this is the approach employed in Ingersoll (2006). The approximate value of a call option computed for a constant exercise policy is given in Appendix B of Ingersoll (2006) as: ${ }^{3}$

\footnotetext{
${ }^{3}$ Ingersoll (2006) also provides an extension that accounts for vesting periods, but his results show that, for our parameter values, this implies only very small differences in the subjective values of compensation.
} 


$$
C \gtrsim \max _{k} C_{b a r r}(S, T, k)
$$

where

$$
\begin{aligned}
C_{\text {barr }}= & \tilde{S}\left(S, T ;\left\{S_{T}>X\right\} \&\left\{S_{\max }<k\right\}\right) \\
& -X \tilde{D}\left(S, T ;\left\{S_{T}>X\right\} \&\left\{S_{\max }<k\right\}\right)+(k-X) \tilde{T}(S, T, k),
\end{aligned}
$$

where $\tilde{S}$ and $\tilde{D}$ are a digital share and a digital option, respectively, and $\tilde{T}$ is a first-touch digital. Ingersoll shows that the formulas for these three digital contracts are ${ }^{4}$

$$
\begin{gathered}
\tilde{S}\left(S, T ;\left\{S_{T}>X\right\} \&\left\{S_{\max }<k\right\}\right)= \\
S e^{-\hat{q} T}\left\{\Phi\left(h_{X}^{+}\right)-\Phi\left(h_{k}^{+}\right)-\left(\frac{k}{S}\right)^{2(\zeta+1)}\left[\Phi\left(h_{X S^{2} / k^{2}}^{+}\right)-\Phi\left(h_{S^{2} / k}^{+}\right)\right]\right\}, \\
\tilde{D}\left(S, T ;\left\{S_{T}>X\right\} \&\left\{S_{\max }<k\right\}\right)= \\
e^{-\hat{r} T}\left\{\Phi\left(h_{X}^{-}\right)-\Phi\left(h_{k}^{-}\right)-\left(\frac{k}{S}\right)^{2 \zeta}\left[\Phi\left(h_{X S^{2} / k^{2}}^{-}\right)-\Phi\left(h_{S^{2} / k}^{-}\right)\right]\right\}, \\
\tilde{T}(S, T, k)=\left(\frac{k}{S}\right)^{\zeta-k} \Phi\left(H_{k}^{+}\right)+\left(\frac{k}{S}\right)^{\zeta+k} \Phi\left(H_{k}^{-}\right),
\end{gathered}
$$

where

$h_{X}^{ \pm}=\frac{\ln (S / X)+\left(\hat{r}-\hat{q} \pm \frac{1}{2} \sigma^{2}\right) T}{\sigma \sqrt{T}}$,

\footnotetext{
${ }^{4}$ Note that we use the subjective risk-neutral process, which has $\hat{r}$ and $\hat{q}$, in this equation. The formulas presented in Appendix B in Ingersoll (2006) apply generally. For calculating the market value, the risk-neutral stochastic process, with $r$ and $q$, would be used (see p. 470).
} 
$\hat{r}=r-\rho \theta^{2} v^{2}$,

$\zeta=\left[(\hat{r}-\hat{q}) / \sigma^{2}\right]-\frac{1}{2}$,

$H_{k}^{ \pm}=\frac{\ln (S / k)+\kappa \sigma^{2} T}{\sigma \sqrt{T}}$,

and

$\kappa=\sqrt{\zeta^{2}+\left(2 \hat{r} / \sigma^{2}\right)}$.

The following primitives are needed to calculate these terms (in addition to the variables defined in Internet Appendix A.1 already):

1. $X$ is the strike price. We assume that options are granted at the money, so that the strike price is equal to the stock price on the grant date.

2. $r$ is the risk-free rate. We use ExecuComp item bs_interest for 1993 to 2005 and the 1-year treasury rate for 2006 to 2009.

3. $T$ is the option maturity. We assume a stock option maturity of 10 years.

One optimization step - determining the optimal exercise policy $k$ - is needed to compute the subjective value of a given stock option. The Stata code for this calculation is available upon request.

Finally, we multiply the subjective value of a given stock option with the number of options (ExecuComp item option_awards_num) to obtain the subjective value of a stock option grant.

In a few cases we cannot closely replicate the Black-Scholes option values as recorded in ExecuComp. In our empirical analysis we therefore exclude those observations. This ensures that in applying the subjective value adjustment we capture only differences coming from the underdiversification and risk-aversion of CEOs. 


\section{B. Turnover Risk Premia due to Career Concerns}

In this section we present a simple model of lifetime utility which we then use to calibrate risk premia that can be attributed to uncertainty about future labor income, i.e., to career concerns. ${ }^{5}$

\section{B.1. Model}

Assume that the CEO derives utility from income, $\tilde{w}_{t}$, in each period over the course of his professional life according to the CRRA utility function $u\left(\tilde{w}_{t}\right)=\tilde{w}_{t}^{1-\rho} /(1-\rho)$.

Importantly, for the purposes of this Internet Appendix, it is useful to think of this income as the certainty-equivalent cash amount that the CEO would be willing to accept for a pay package that may contain non-cash components. As is well-known, equity risk, forfeiture risk, vesting restrictions, and limited tradability all combine into implying a potentially sizable difference between the market value of compensation packages and the value to the executive. We assume that these risks have been taken into account and that there is only one type of uncertainty remaining in this model: that due to the risk of losing the job and losing future income.

Denoting by $\beta$ the time-discount factor, the CEO's expected lifetime utility is given by

$$
E\left[\sum_{t=1}^{T_{R}} \beta^{t} u\left(\tilde{w}_{t}\right)\right] .
$$

where $T_{R}$ are the years until the CEO reaches retirement. Note that, to keep the model simple, we assume that the $\mathrm{CEO}$ receives utility from income rather than consumption, and that the utility is realized when the CEO receives that income, so that there is no scope for maximizing lifetime utility through saving and consumption smoothing.

Current income of the CEO is given by $w$. To reflect the adverse consequences of forced turnover we assume that income declines by a fraction $d$ when the CEO is dismissed and remains at the new level until retirement. Thus, uncertain income can be written as

\footnotetext{
${ }^{5}$ The literature on career concerns (e.g., Gibbons and Murphy (1992)) has long considered the incentive effects of career concerns. Here, we are concerned with the relationship between turnover risk and the level of pay.
} 


$$
\tilde{w}_{t}=w\left(1-d \cdot \mathbf{1}\left(T_{f}<t\right)\right)
$$

where $w$ is current income, $\mathbf{1}($.$) is an indicator function equal to one if the condition in parentheses$ is true, and $T_{f}$ is the year of forced turnover. Substituting (B2) into (B1) and noting that with power utility, utility of current income can be factored and placed outside the expectations operator, expected utility can be written as

$$
E\left[\sum_{t=1}^{T_{R}} \beta^{t} u\left(\tilde{w}_{t}\right)\right]=u(w) \cdot \sum_{t=1}^{T_{R}} \beta^{t} E\left[u\left(\left(1-d \cdot \mathbf{1}\left(T_{f}<t\right)\right)\right)\right] .
$$

Lifetime utility of a certain income stream $w^{*}$ is given by

$$
\sum_{t=1}^{T_{R}} \beta^{t} u\left(w^{*}\right)
$$

The certainty equivalent income is given by the safe income $w^{*}$ that solves

$$
E\left[\sum_{t=1}^{T_{R}} \beta^{t} u\left(\tilde{w}_{t}\right)\right]=\sum_{t=1}^{T_{R}} \beta^{t} u\left(w^{*}\right)
$$

This equation can be solved in closed form for the ratio of certainty equivalent to risky income:

$$
\frac{w^{*}}{w}=\left[\frac{\sum_{t=1}^{T_{R}} \beta^{t} E\left[\left(1-d \cdot \mathbf{1}\left(T_{f}<t\right)\right)^{1-\rho}\right]}{\sum_{t=1}^{T_{R}} \beta^{t}}\right]^{1 /(1-\rho)}
$$

Two aspects of equation (B6) are noteworthy: First, due to the power utility specification and the assumption that income shocks due to forced turnover are proportional to income before dismissal, the percentage risk premium, $1-w / w^{*}$, does not depend on the level of wealth. Second, the risk premium is positive even for a risk-neutral CEO. This is due to the fact that the income shock distribution has negative mean. ${ }^{6}$

\footnotetext{
${ }^{6}$ Note that our notion of risk premia is different from the more common notion where risk is defined as a mean-preserving spread. With the latter definition, risk premia can only occur in the presence of risk aversion.
} 
Writing out the expectation in the denominator of equation (B6) and assuming, again for simplicity, that the one year hazard rate, $P\left(T_{f}<t+1 \mid T_{f}>t\right) \equiv p$, is constant, we obtain

$$
\begin{aligned}
\frac{w^{*}}{w} & =\left[\frac{\sum_{t=1}^{T_{R}} \beta^{t}\left[P\left[T_{f} \leq t\right] \cdot(1-d)^{1-\rho}+P\left[T_{f}>t\right]\right]}{\sum_{t=1}^{T_{R}} \beta^{t}}\right]^{1 /(1-\rho)} \\
& =\left[\frac{\sum_{t=1}^{T_{R}} \beta^{t}\left[\left(1-(1-p)^{t}\right) \cdot(1-d)^{1-\rho}+(1-p)^{t}\right]}{\sum_{t=1}^{T_{R}} \beta^{t}}\right]^{1 /(1-\rho)}
\end{aligned}
$$

Equation (B7) shows that the risk premium, $1-w^{*} / w$, is a function of the five parameters $T_{R}, \beta, \rho, d$, and $p$.

\section{B.2. Numerical Results}

We now calibrate the model to a realistic range of these parameter values, and compute the corresponding risk premia. We set the years until retirement to $T_{R}=10$, as the average CEO in our dataset is about $55 \mathrm{old}$, and fix the time preference rate $\beta$ at 0.96 . We vary the other parameters within the following ranges: The coefficient of relative risk aversion, $\rho$, takes the values 0,2 , or 3 . While values for $\rho$ of 2 to 3 correspond to standard estimates, the case $\rho=0$ serves as a benchmark, and helps to disentangle the effect of risk aversion from the (negative) mean effect of forced turnover on future labor income. The percentage decline of future income due to forced turnover varies between $10 \%$ and 100\%. Conditional on finding a subsequent job, a 20\%-75\% decrease in pay appears realistic in light of the empirical evidence in Fee and Hadlock (2004). ${ }^{7}$ Finally, we vary the one-year forced turnover probability, $p$, in a range of $1 \%$ to $10 \%$.

Table B-I presents the calibration results. As expected, risk premia are increasing in the coef-

\footnotetext{
${ }^{7}$ They find that (1) in three quarters of cases of turnovers (even voluntary ones), new salaries are lower than prior ones, (2) only a third of CEOs who were fired reappear at other employers in their sample, (3) those who do obtain new employment after having been fired do so at firms approximately one-tenth the size of their former employer, and (4) those for whom salary data is available (and who are, therefore, likely to have gotten the best new jobs), experience pay cuts on the order of $20 \%$. While the $20 \%$ pay loss arguably understates the average earnings consequences of forced turnover, Fee and Hadlock's findings on the size of subsequent employers allows one to obtain a second approximate benchmark. We can translate the decrease in firm size by a factor of ten into the corresponding pay reduction using the coefficient of log firm size in a regression of log total compensation on firm size. Consistent with other studies on CEO compensation, we find this coefficient to be between 0.30 and 0.40 . This implies that a decline in firm size by a factor of ten is associated with $66 \%-75 \%$ lower pay. Thus, dismissed CEOs are likely to earn about one quarter to one third of their pre-turnover pay. Note that both the $20 \%$ and $75 \%$ estimates are conditional on the CEO finding a new employer at all. In our sample of S\&P 1500 firms only 11 out of the 639 fired CEOs subsequently regain a CEO post within the same universe of firms. On average, these CEOs take on their subsequent job only four years after they have been dismissed by their former employer.
} 
ficient of relative risk aversion, the assumed percentage decline in pay following forced turnover, and the forced turnover probability. Risk premia for a $100 \%$ decline in future pay following turnover are not defined for a CRRA utility function with strictly positive $\rho$, because expected utility becomes infinitely negative if there is a chance of receiving zero income at any point in time.

When reading through the lines from left (low pay decline following turnover) to right (high pay decline), the turnover risk premium increases linearly with the pay decline if CEOs are risk neutral, but it is increasingly convex in the pay decline as risk aversion becomes larger. This is a reflection of the fact that agents with CRRA utility are approximately risk-neutral with respect to small risks, but become increasingly risk averse as the size of the risk increases Arrow (1971). When reading through the columns from top (low turnover risk) to bottom (high turnover risk), the risk premium is concave in turnover risk.

For realistic degrees of risk aversion $(\rho \epsilon(2,3))$ and pay losses following forced turnover of around $50 \%$, the risk premium for a one percentage point increase in the forced turnover rate is around $3.5 \%$, but can reach close to $10 \%$ for pay losses of around $75 \%{ }^{8}$ This number can be compared to the coefficient estimates in our regressions with subjective values of compensation as the dependent variable.

\footnotetext{
${ }^{8}$ If the CEO had a contractual severance agreement (which is not modeled in this analysis), the premium would be lower; if the CEO does not immediately find a new job upon being dismissed, the premium would be higher.
} 


\section{Table B-I}

\section{Risk Premia due to Career Concerns}

The table presents calibrated risk premia that arise from the adverse consequences of forced turnover on future earning opportunities. Risk premia are defined as the percentage difference between current pay (in certainty-equivalent terms), which is subject to a permanent negative shock if forced turnover occurs, and the safe amount of pay that yields the same lifetime utility. Risk premia are computed using equation (A7). The model parameters required for calibration are the years until retirement, $\mathrm{T}$, the time preference, $\beta$, the coefficient of relative risk aversion, $\rho$, the expected proportional loss of future pay conditional on forced turnover, $d$, and the one-year turnover probability, $p . T$ and $\beta$ are fixed at 10 years and 0.96 , respectively. Panel A assumes risk neutrality $(\rho=0)$ while Panels B and C use $\rho=2$ and $\rho=3$, respectively. The turnover probability, $p$, is varied between $1 \%$ and $10 \%$. The expected pay loss following forced turnover, $d$, varies between $10 \%$ and $100 \%$.

\begin{tabular}{|c|c|c|c|c|c|c|c|}
\hline \multicolumn{8}{|c|}{ Panel A: $\rho=0$} \\
\hline & \multicolumn{7}{|c|}{ Pay loss following turnover } \\
\hline Turnover rate & $10 \%$ & $20 \%$ & $30 \%$ & $40 \%$ & $50 \%$ & $75 \%$ & $100 \%$ \\
\hline $1 \%$ & 0.50 & 1.00 & 1.51 & 2.01 & 2.51 & 3.76 & 5.02 \\
\hline $2 \%$ & 0.98 & 1.95 & 2.93 & 3.90 & 4.88 & 7.32 & 9.76 \\
\hline $3 \%$ & 1.42 & 2.85 & 4.27 & 5.69 & 7.12 & 10.67 & 14.23 \\
\hline $4 \%$ & 1.85 & 3.69 & 5.54 & 7.38 & 9.23 & 13.84 & 18.46 \\
\hline $5 \%$ & 2.24 & 4.49 & 6.73 & 8.98 & 11.22 & 16.84 & 22.45 \\
\hline \multirow[t]{2}{*}{$10 \%$} & 3.93 & 7.87 & 11.80 & 15.73 & 19.67 & 29.50 & 39.33 \\
\hline & \multicolumn{6}{|c|}{ Panel B: $\rho=2$} & \\
\hline & \multicolumn{7}{|c|}{ Pay loss following turnover } \\
\hline Turnover rate & $10 \%$ & $20 \%$ & $30 \%$ & $40 \%$ & $50 \%$ & $75 \%$ & $100 \%$ \\
\hline $1 \%$ & 0.55 & 1.24 & 2.11 & 3.24 & 4.78 & 13.09 & - \\
\hline $2 \%$ & 1.07 & 2.38 & 4.01 & 6.11 & 8.89 & 22.64 & - \\
\hline $3 \%$ & 1.56 & 3.44 & 5.75 & 8.67 & 12.46 & 29.92 & - \\
\hline $4 \%$ & 2.01 & 4.41 & 7.33 & 10.96 & 15.58 & 35.64 & - \\
\hline $5 \%$ & 2.43 & 5.31 & 8.78 & 13.02 & 18.33 & 40.24 & - \\
\hline \multirow[t]{3}{*}{$10 \%$} & 4.19 & 8.95 & 14.43 & 20.77 & 28.23 & 54.13 & - \\
\hline & \multicolumn{6}{|c|}{ Panel C: $\rho=3$} & \\
\hline & \multicolumn{7}{|c|}{ Pay loss following turnover } \\
\hline Turnover rate & $10 \%$ & $20 \%$ & $30 \%$ & $40 \%$ & $50 \%$ & $75 \%$ & $100 \%$ \\
\hline $1 \%$ & 0.58 & 1.38 & 2.51 & 4.18 & 6.77 & 24.47 & - \\
\hline $2 \%$ & 1.13 & 2.64 & 4.72 & 7.69 & 12.05 & 36.29 & - \\
\hline $3 \%$ & 1.63 & 3.78 & 6.67 & 10.67 & 16.29 & 43.52 & - \\
\hline $4 \%$ & 2.10 & 4.82 & 8.41 & 13.23 & 19.77 & 48.49 & - \\
\hline $5 \%$ & 2.53 & 5.77 & 9.97 & 15.46 & 22.70 & 52.15 & - \\
\hline $10 \%$ & 4.32 & 9.51 & 15.77 & 23.29 & 32.27 & 61.93 & - \\
\hline
\end{tabular}




\section{Additional Tables}

This section provides additional tables that supplement the analysis in the main paper.

Table C-I is an expanded version of Table III in the paper. It shows all first-stage regressions, including those with industry semi-volatility as the instrument.

Table C-II is an expanded version of Table V in the paper. It shows all second-stage regressions, including those with industry semi-volatility as the instrument.

Table C-III is an expanded version of Table VI in the paper. It shows all reduced form regressions, including those with industry semi-volatility.

Table C-IV is a variant of Table V in the paper. It uses volatility-adjusted total compensation as the dependent variable in the second stage.

Table C-V sets all missing ratings to the mean of their industry.

Table C-VI considers the companies in the ExecuComp database over the time period 2006 to 2009, that is, after the implementation of FAS 123R.

Table C-VII presents further robustness checks. 


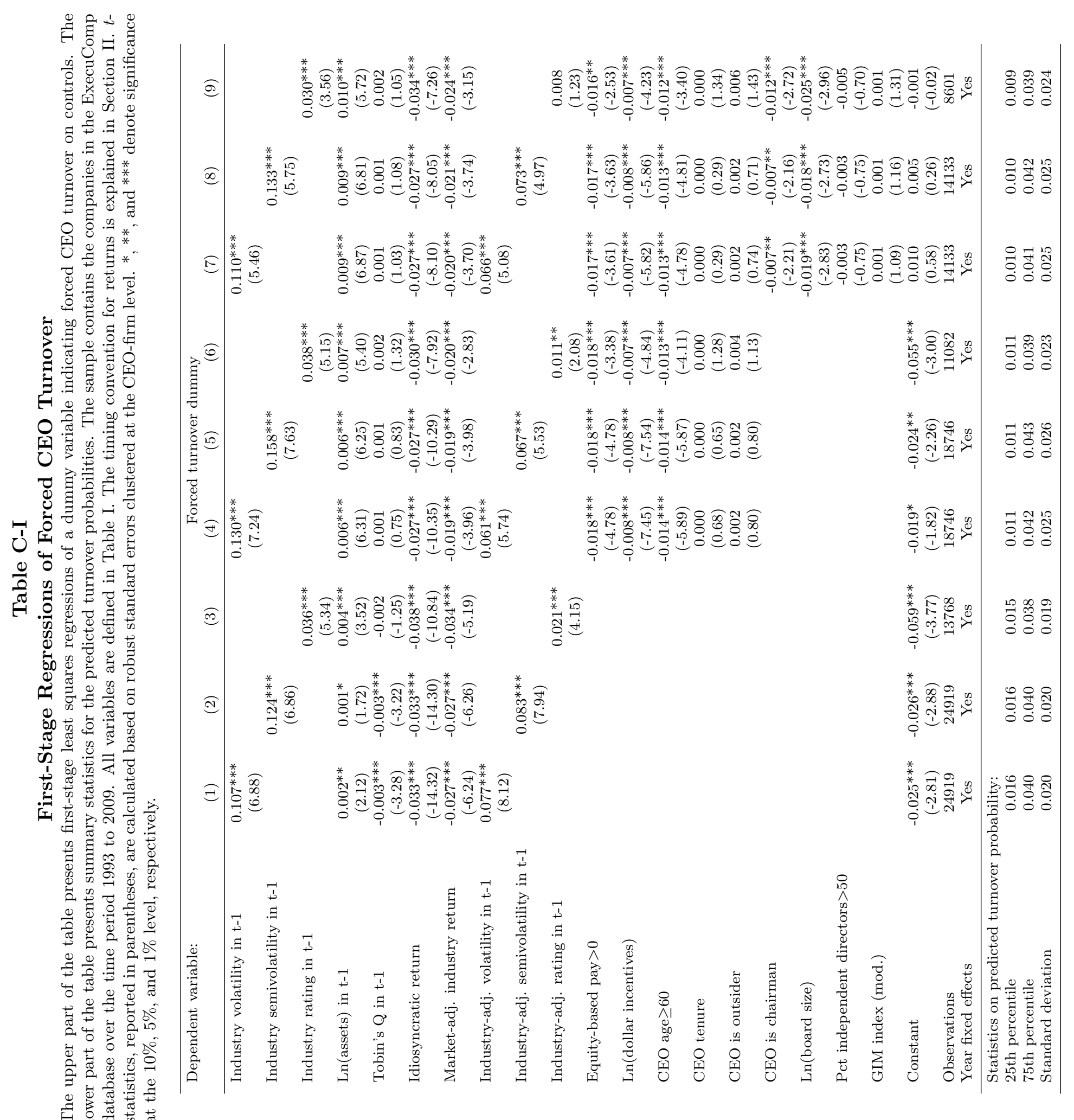




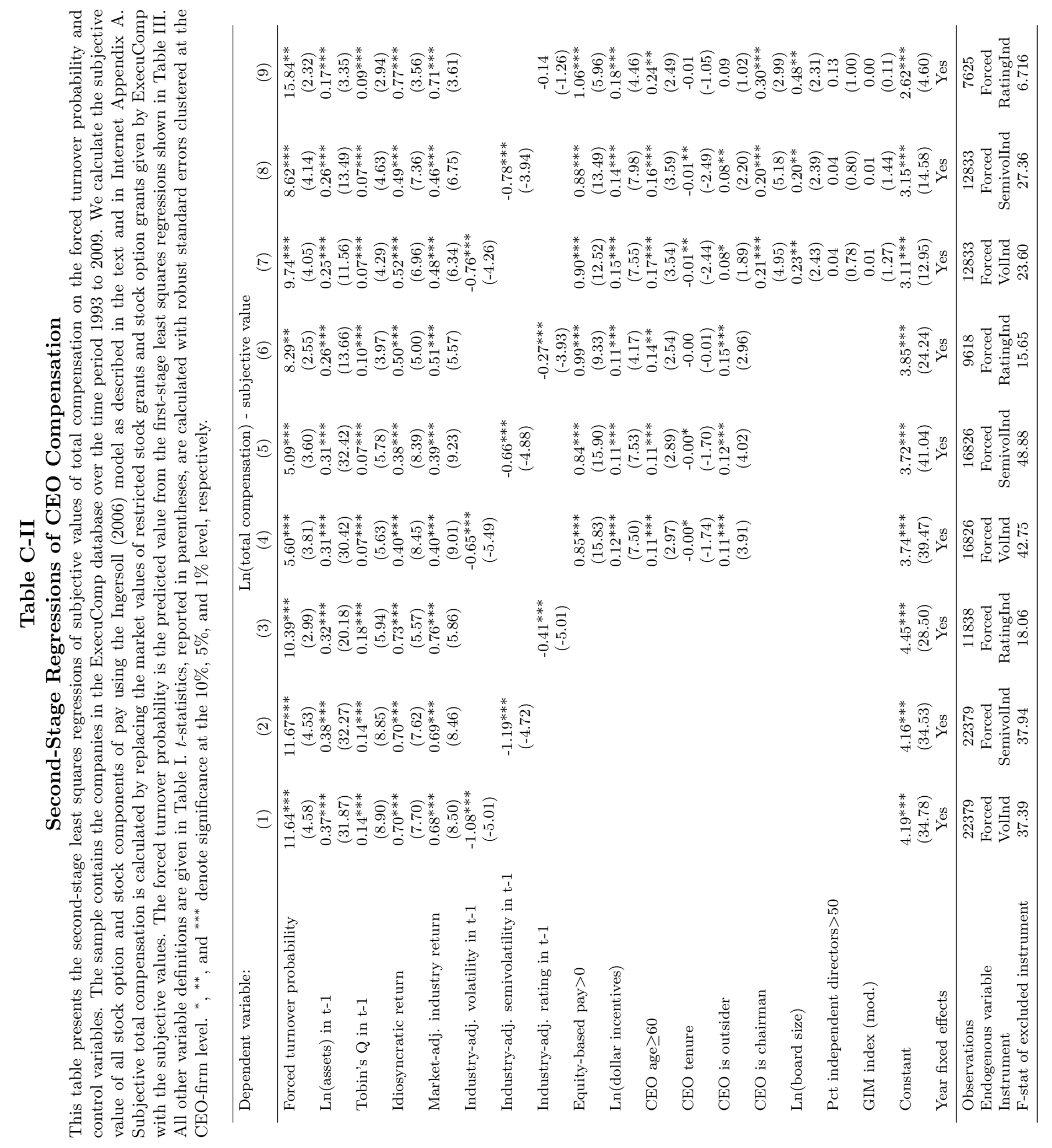




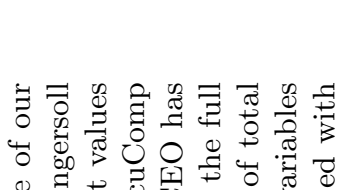

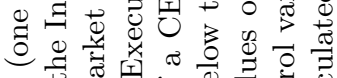

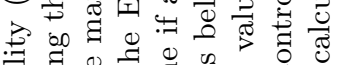
글

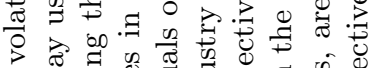

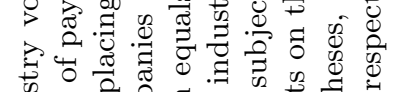

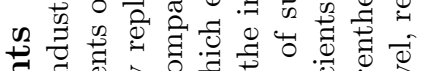

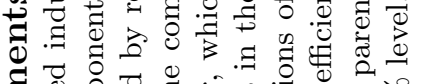

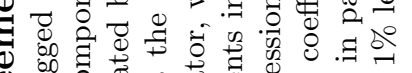

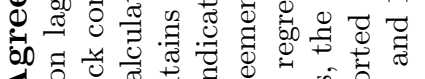

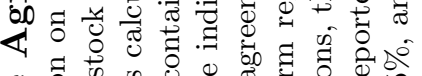

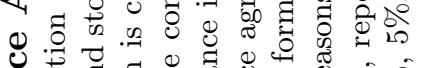

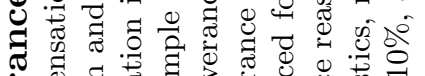

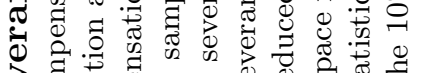

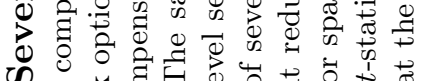

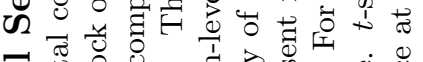

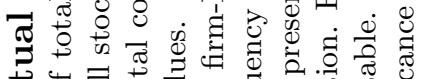

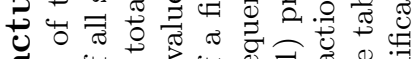

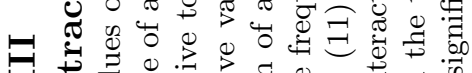
U

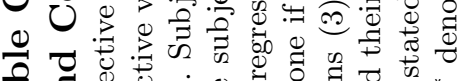

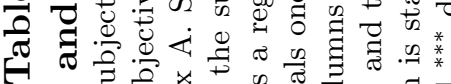

与

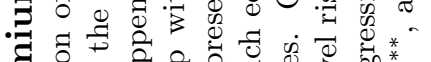

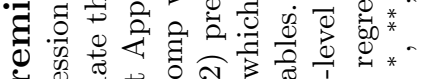
Q

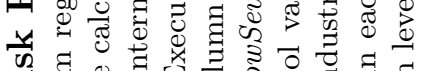

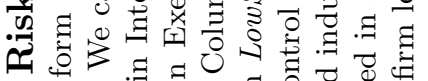

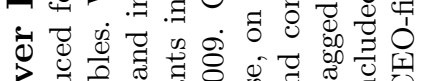
等 然 月

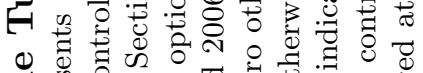

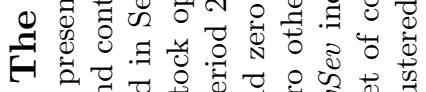

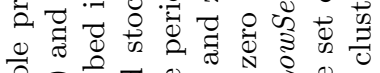

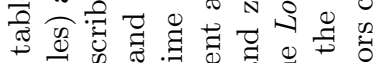
을

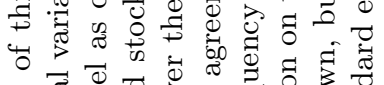

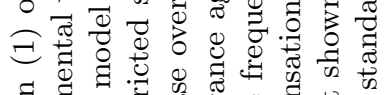

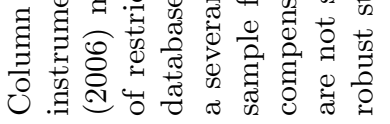

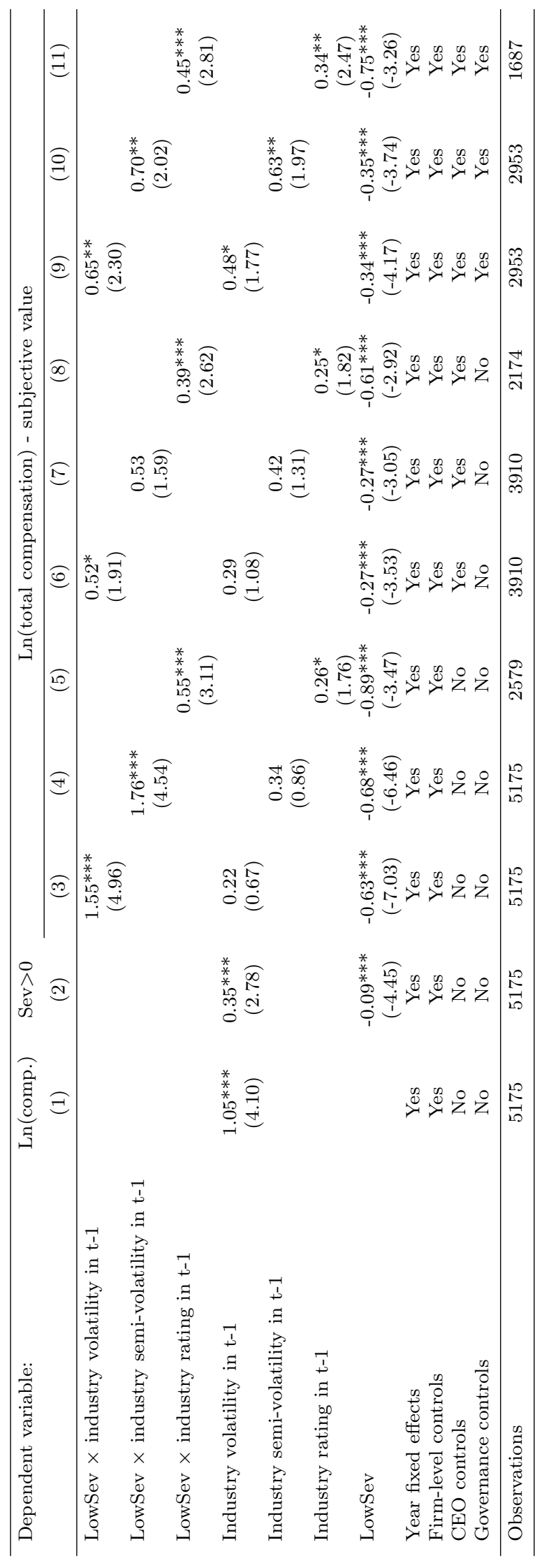




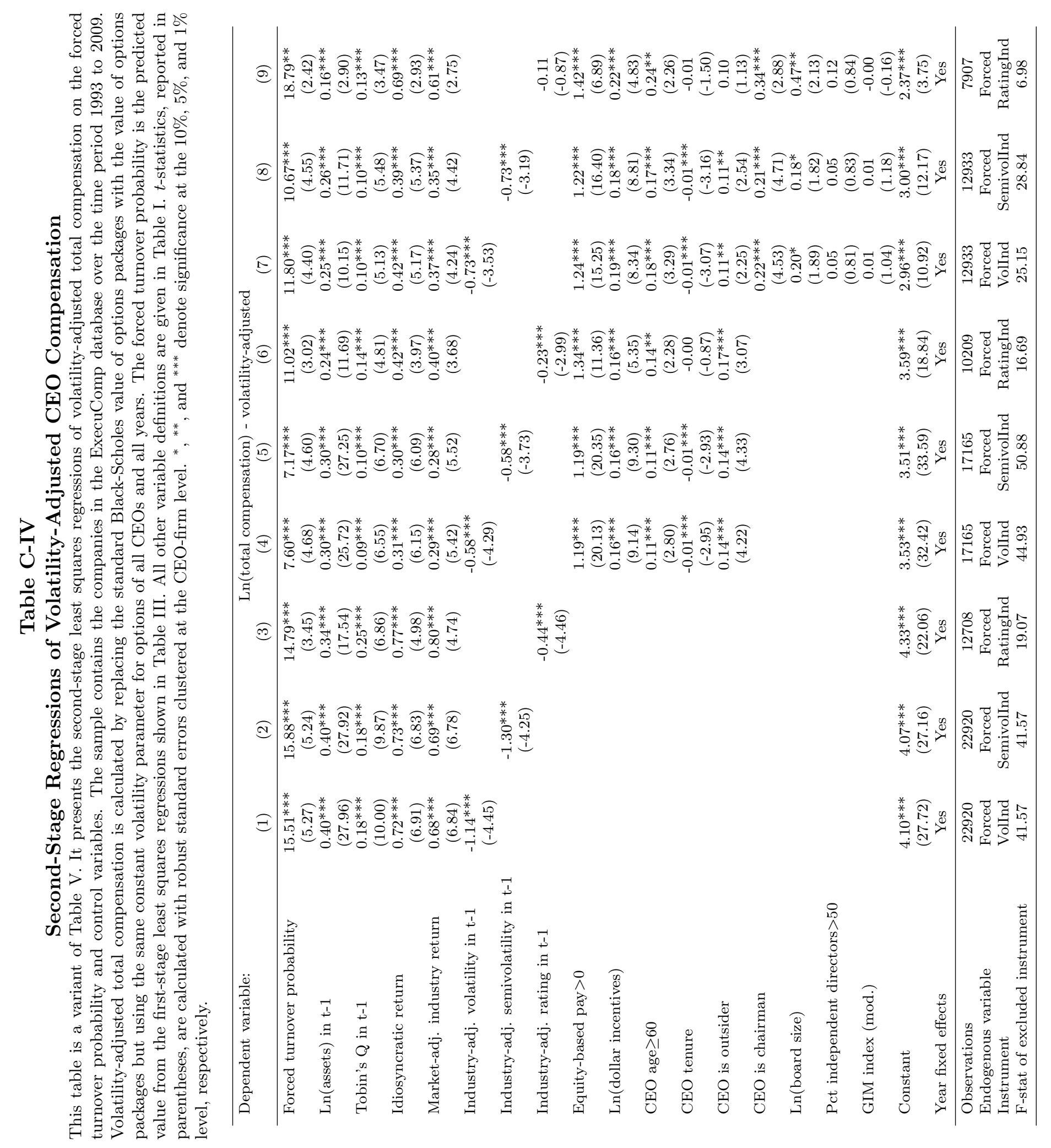




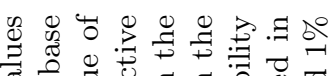

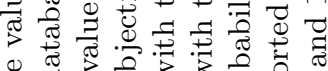

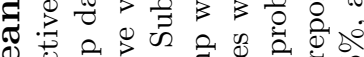
. वे ठ⿹ 药

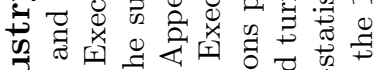

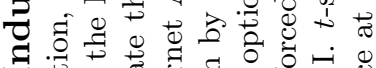

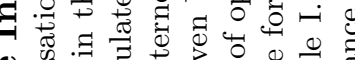
Q † 0 잉 สే .

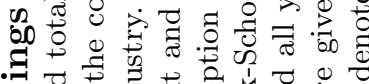

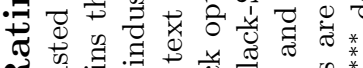

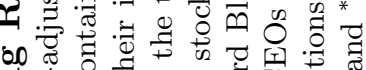

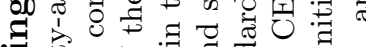

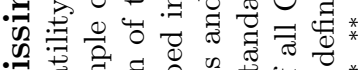

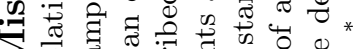

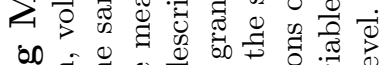

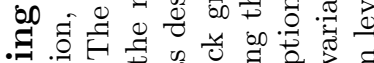

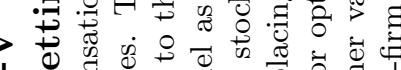
1
0

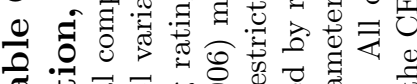

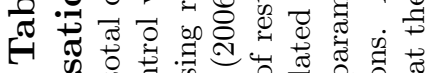

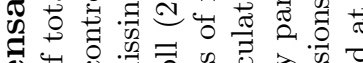
के ही

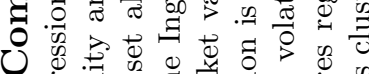

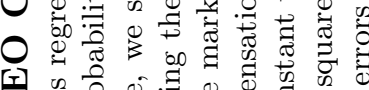

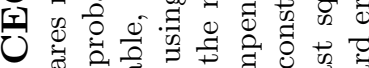

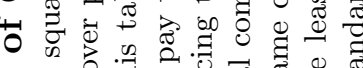
प . की

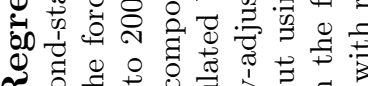

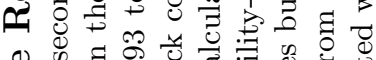
نo 0 出

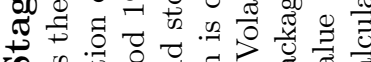

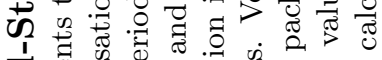

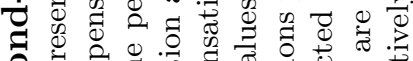

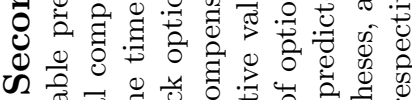
ॠ

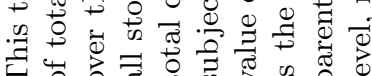

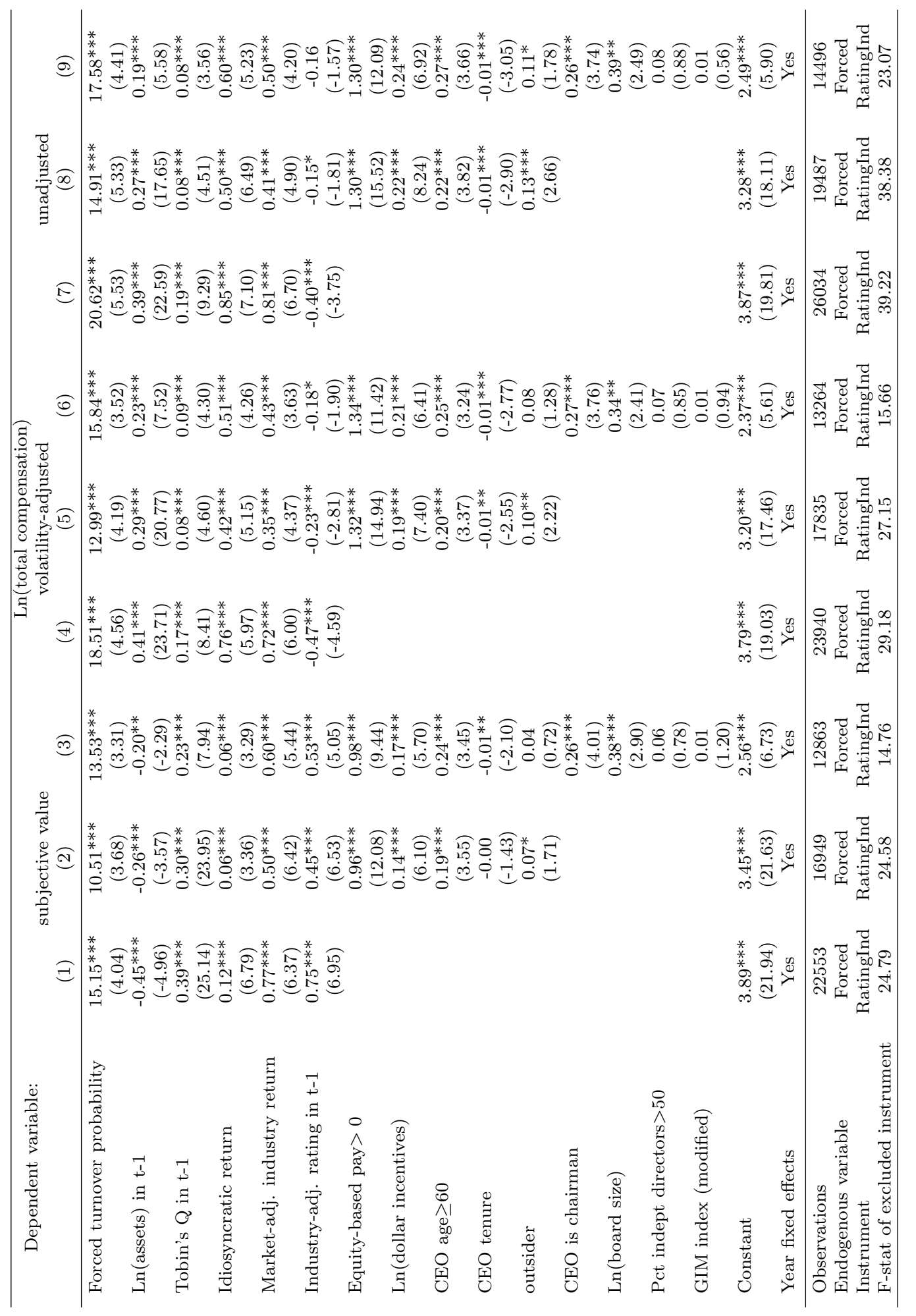




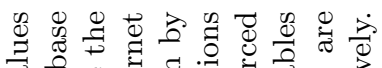

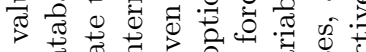

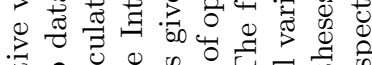

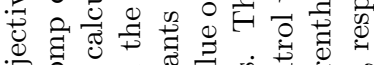

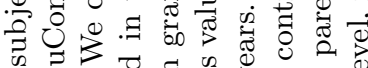

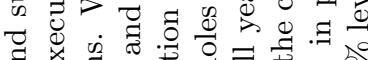

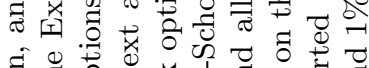

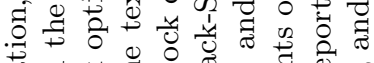

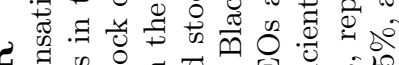
\% ज्ञ

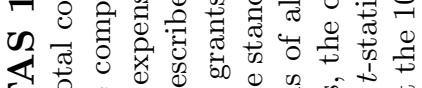

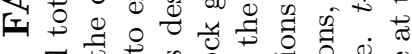
包总

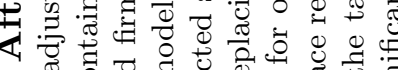

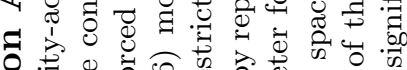
을

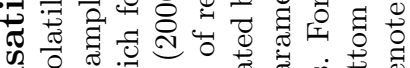
을

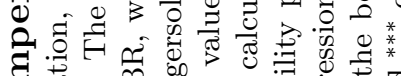

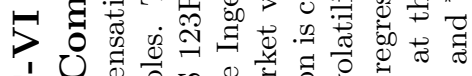

0 ن

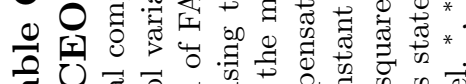

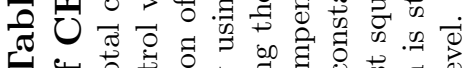

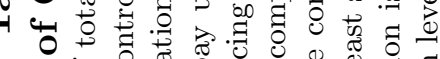

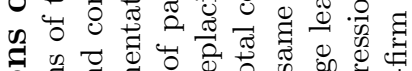

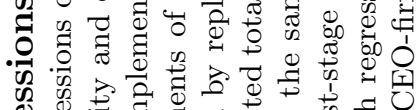

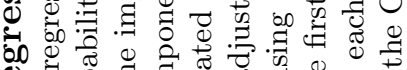

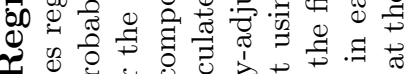

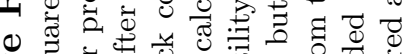

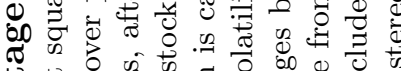
की

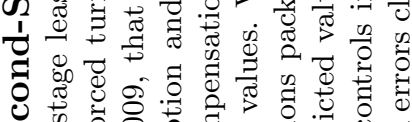

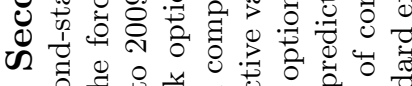

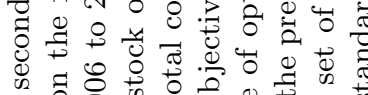

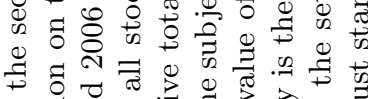

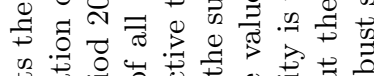

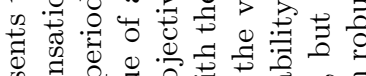

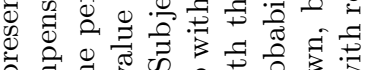

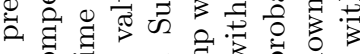
요의

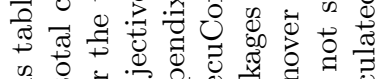

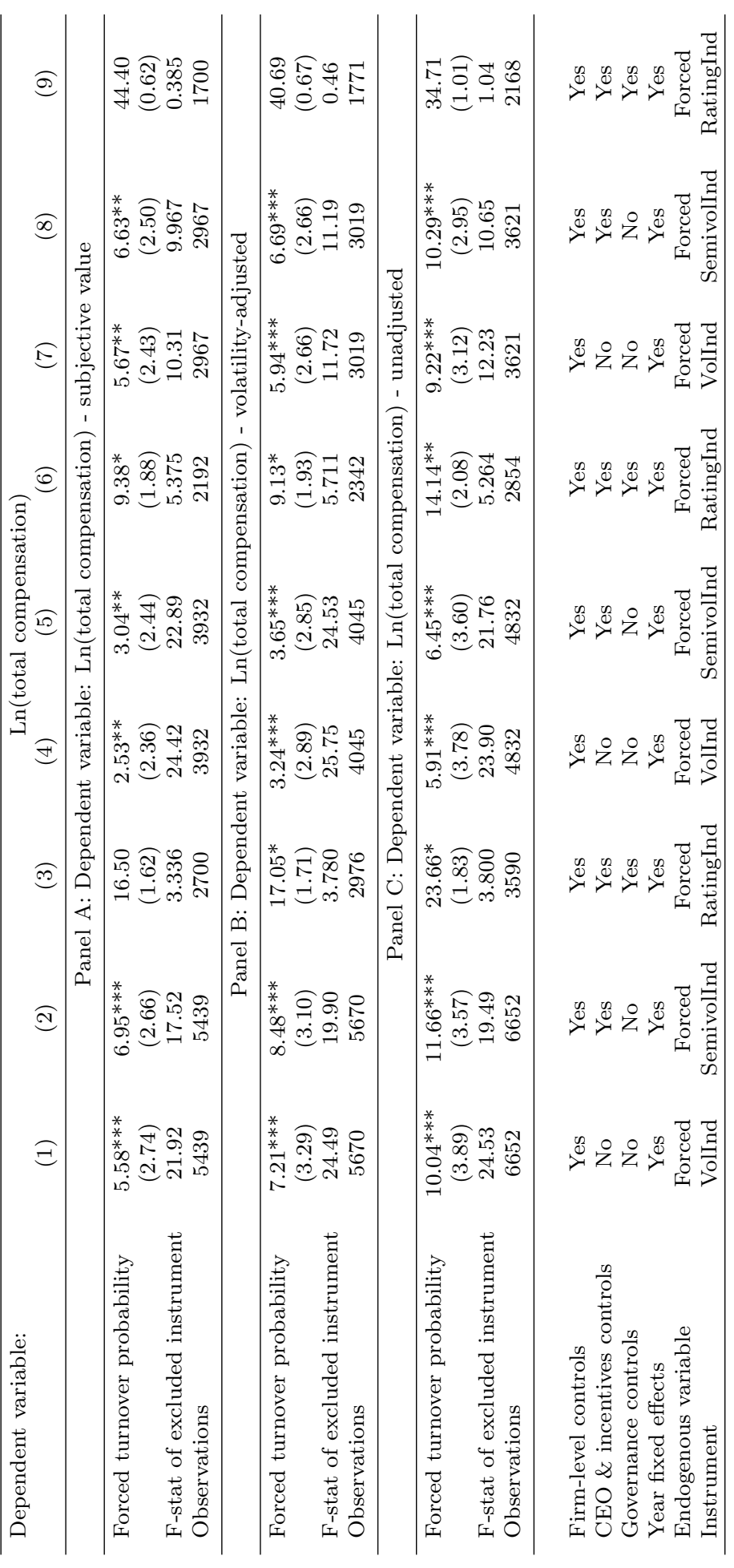

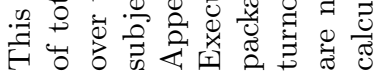

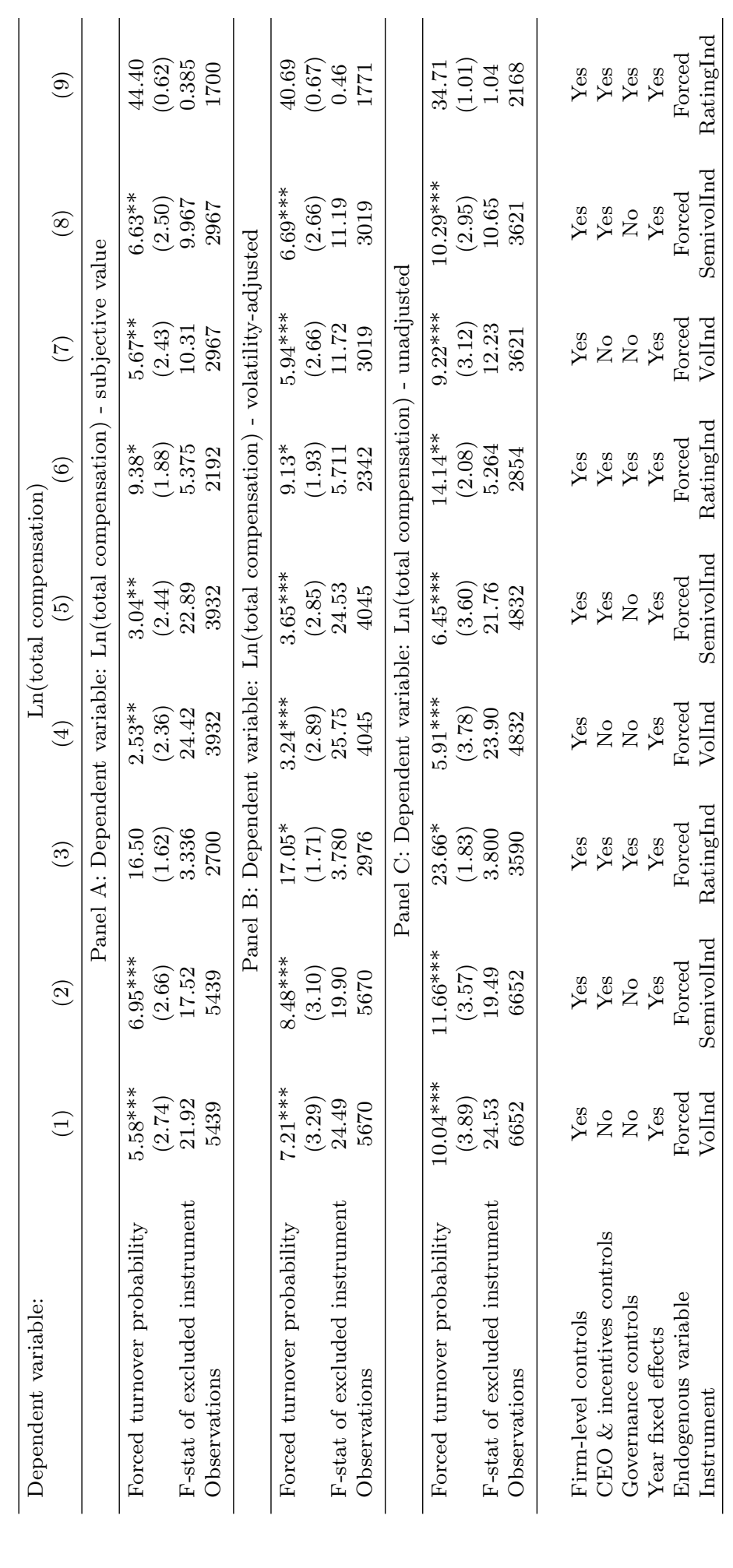




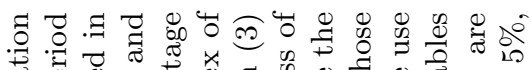

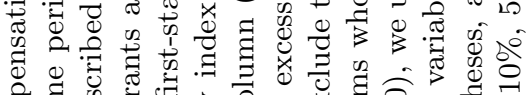

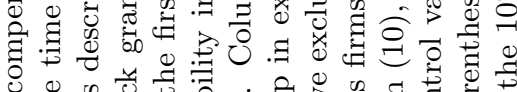

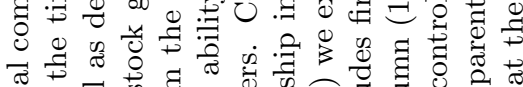

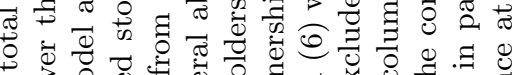
पे

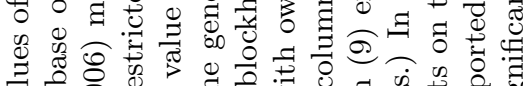

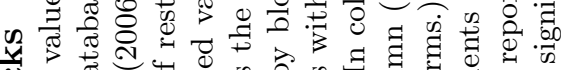

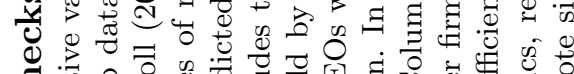

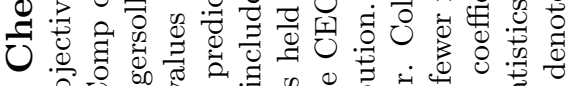

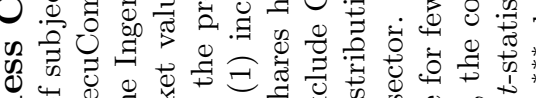

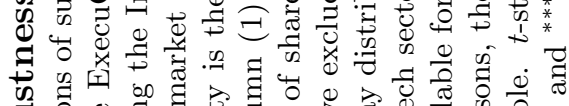

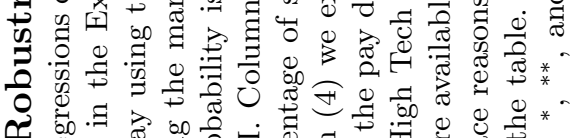

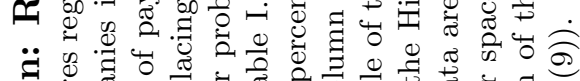

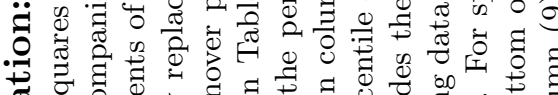

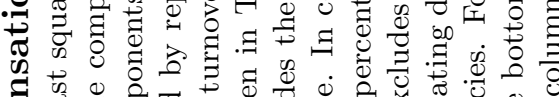

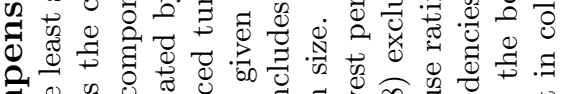

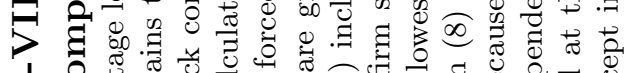
U ठํ.

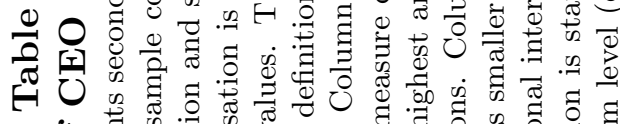

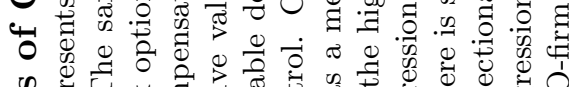

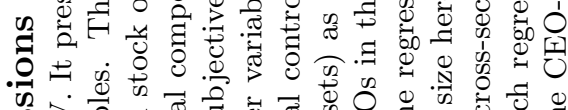

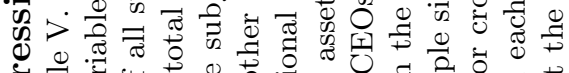
so

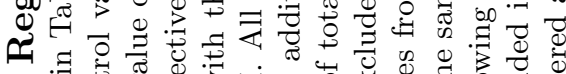

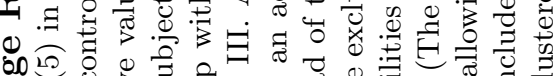

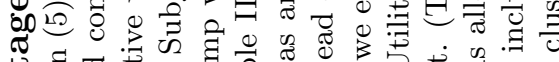

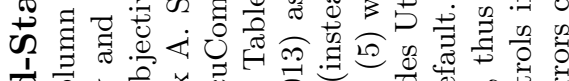

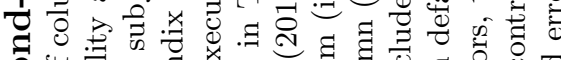

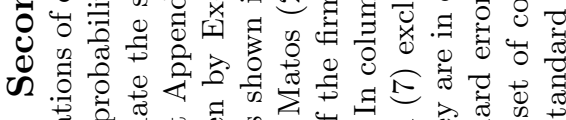

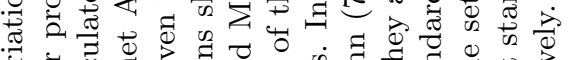

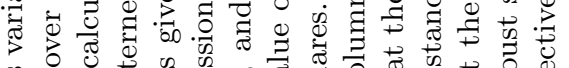

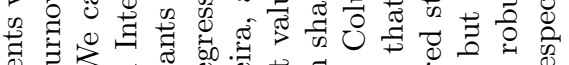

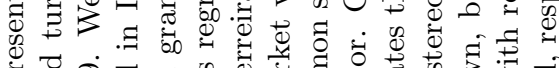

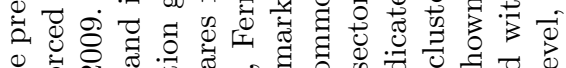
융 过

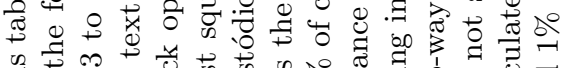

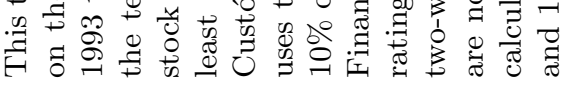

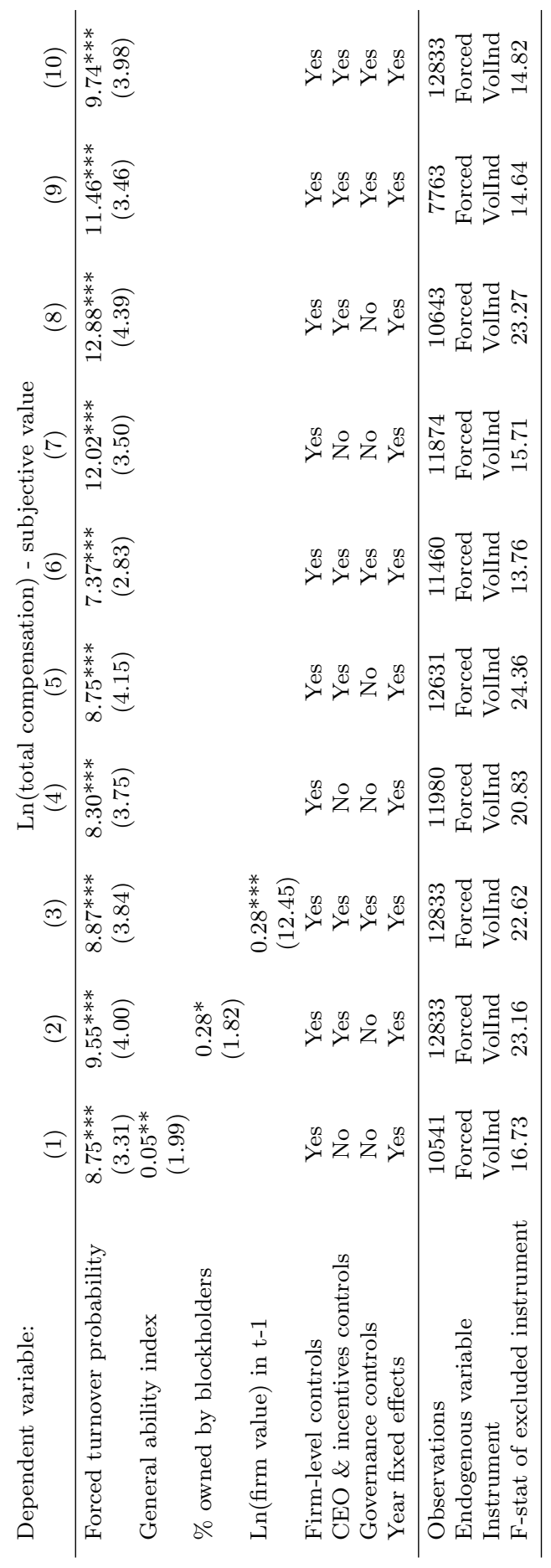




\section{References}

Arrow, Kenneth, 1971, Essays in the Theory of Risk-Bearing (Markham Publishing Company).

Custódio, Cláudia, Miguel A. Ferreira, and Pedro Matos, 2013, Generalists versus specialists: Lifetime work experience and chief executive officer pay, Journal of Financial Economics 108, 471-492.

Fee, C. Edward, and Charles J. Hadlock, 2004, Management turnover across the corporate hierarchy, Journal of Accounting and Economics 37, 3-38.

Gibbons, Robert, and Kevin J. Murphy, 1992, Optimal incentives in the presence of career concerns, Journal of Political Economy 100, 468-505.

Ingersoll, Jonathan E., 2006, The subjective and objective evaluation of incentive stock options, The Journal of Business 79, 453-487. 